\title{
DEALING WITH DEATH: \\ MEDICAL STUDENTS' EXPERIENCES WITH PATIENT LOSS
}

\author{
Regina M. Pessagno
}

Submitted to the faculty of the University Graduate School in partial fulfillment of the requirements

for the degree

Master of Arts

in the Department of Sociology,

Indiana University

August 2010 
Accepted by the Faculty of Indiana University, in partial fulfillment of the requirements for the degree of Master of Arts.

Carrie E. Foote, Ph.D., Chair

Master's Thesis

Committee

Tamara G.J. Leech, Ph.D.

William P. Gronfein, Ph.D. 


\section{ACKNOWLEDGEMENTS}

I would like to thank the members of my thesis committee who made the process of completing this thesis a great learning experience. Specifically, I thank the chair of my committee, Dr. Carrie Foote for her guidance and support throughout this research process. Finalizing this thesis would not have been possible without Dr. Foote's continuous feedback. I would also like to thank the other members of my committee, Drs. Tamara Leech and William Gronfein, for their valuable advice and comments regarding where I could take this research in the future and what can be done to make it stronger.

To my mom and dad, for their love and encouragement.

Lastly, I would like to thank the 20 students who were generous enough to take time out of their busy schedules to sit down for interviews. 


\section{TABLE OF CONTENTS}

CHAPTER ONE - INTRODUCTION

CHAPTER TWO - BACKGROUND AND SIGNIFICANCE ……………............ 4

I. Medical Socialization around Death Issues .................................................................... 4

II. The Medical Management of Death Anxiety .............................................................. 8

III. Medical Culture Changes around Death Issues ....................................................... 10

IV. Recent Research on Death Anxiety ....................................................................... 11

Limitations of Existing Research.............................................................................. 14

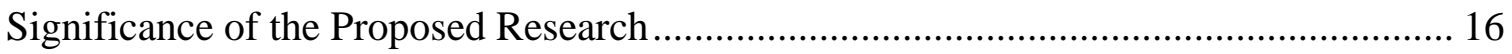

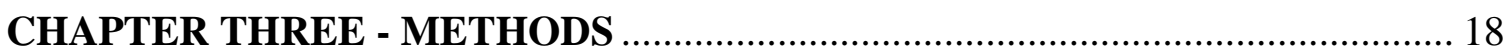

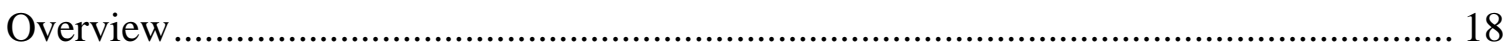

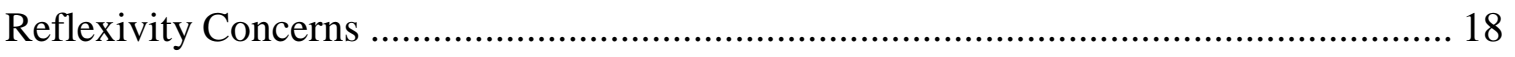

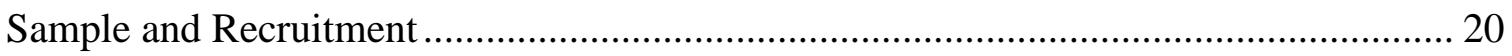

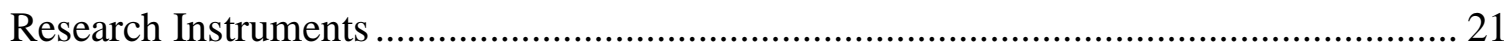

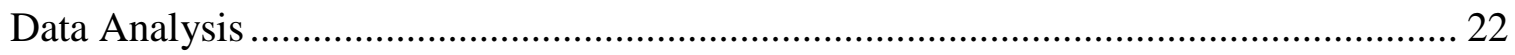

Research Challenges and Risks ............................................................................. 23

Conclusion and Findings Overview..................................................................... 24

CHAPTER FOUR - GROSS ANATOMY LAB EXPERIENCES ............................ 26

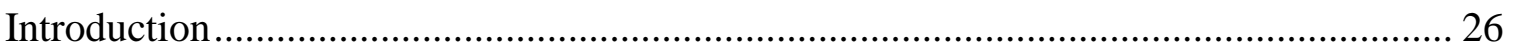

I. Experiencing Anatomy Lab as an Undergraduate Student.......................................... 27

II. Experiencing Anatomy Lab as a Medical Student ..................................................... 28

III. Coping with Discomfort in Anatomy Lab ........................................................... 36

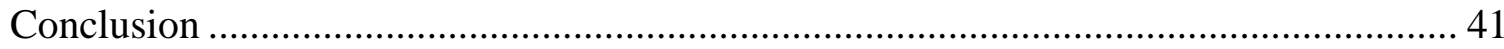




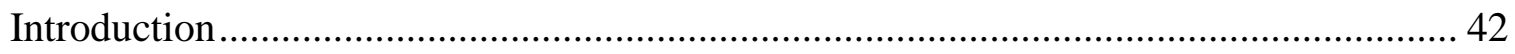

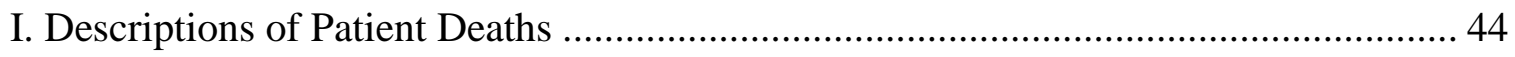

II. Coping with Patient Deaths as a Medical Student ……................................................ 51

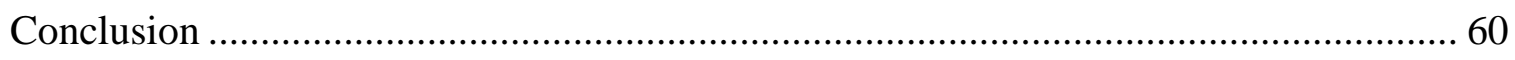

CHAPTER SIX - ATTITUDES TOWARDS PATIENT DEATH ………………..... 62

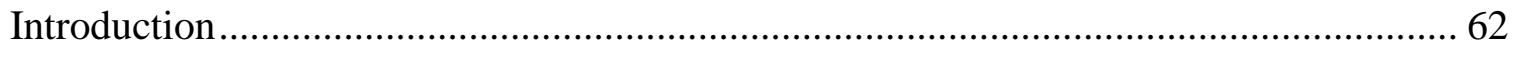

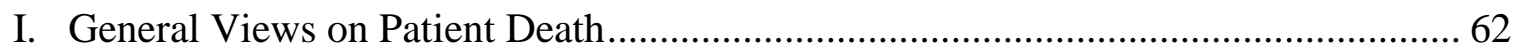

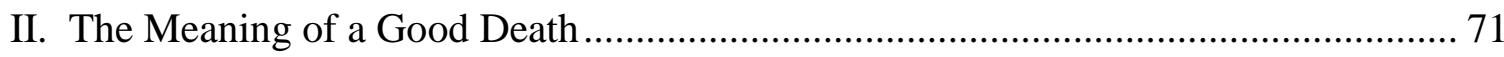

III. Attitudes Towards Physician Assisted Suicide ........................................................... 76

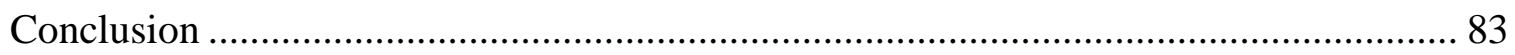

CHAPTER SEVEN - CONCLUSION AND SUMMARY ………………….......... 85

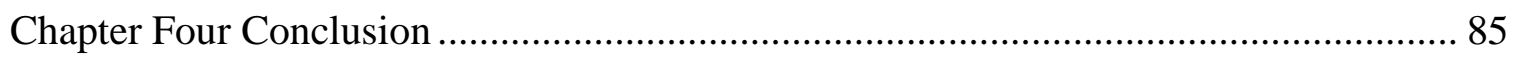

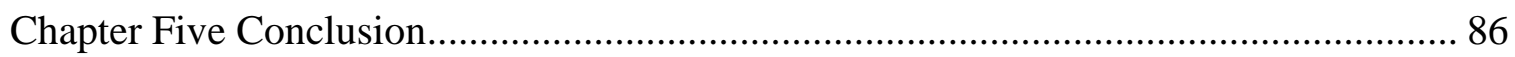

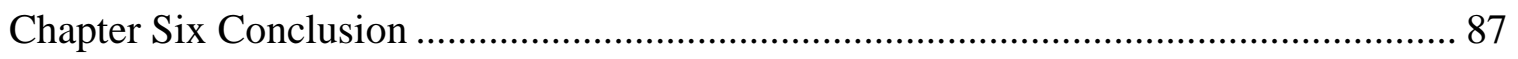

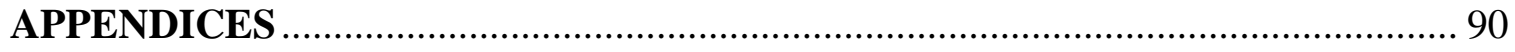

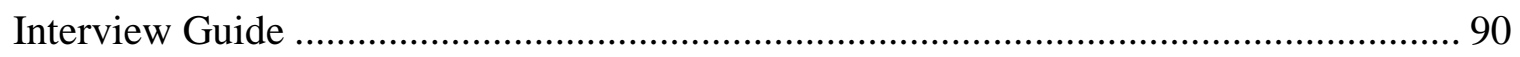

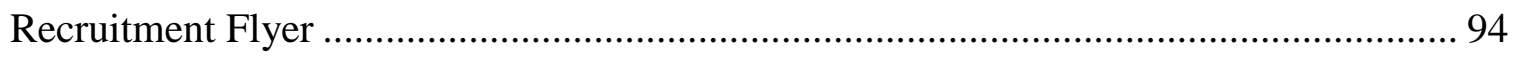

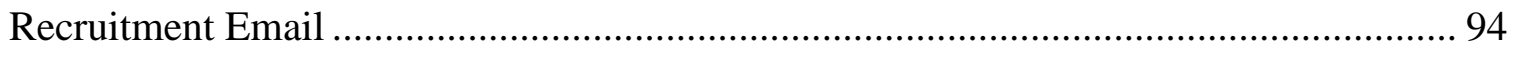

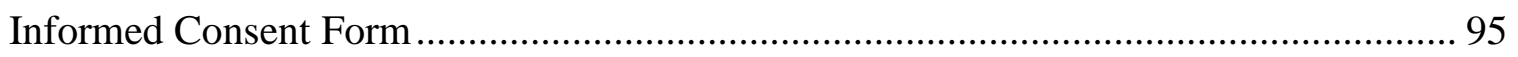

REFERENCES

\section{CURRICULUM VITAE}




\section{CHAPTER ONE - INTRODUCTION}

Some social researchers argue that America is a death-fearing society in which death is generally considered to be a taboo topic (Dickinson and Leming 2007; Hooyman and Kiyak 2008). Under this view, the medical profession is not unique in that it traditionally has been devoted to pro-longing life and averting death. It is during medical school that future doctors begin to experience a professional socialization process that emphasizes the values of pro-longing life and averting death. Several researchers have claimed that the medical view of death defines this natural process as a failure in a system that exists to prolong and save lives (Hooyman and Kiyak 2008; Dickinson and Leming 2007; Dickinson, Still and Tournier 1999; Rappaport and Witzke 1993). The values physicians and students may adopt concerning their views of death and dying may therefore merely be an extension of the values Americans adopt in the general population.

Since we live in a death-fearing society, a paradoxical situation emerges when it comes to the experiences physicians have with dying patients - how do doctors, who are trained to cure individuals, cope when their training is not enough to save a life? What kind of values are being passed from physicians to students concerning attitudes towards patient death during the socialization process that takes place throughout medical school? Also, how do medical students experience death in their work and how do they cope with patient loss? Some researchers have tried to address these questions and have reached varying conclusions.

Dickinson and Pearson (1980) found that physicians who had formal education concerning death and dying were more likely to feel comfortable interacting with dying patients. Kane and Hogan (1985) also found that younger physicians experienced more 
death anxiety than their older counterparts, but did not explore in-depth what constituted such death anxiety. Lastly, Rappaport and Witzke (1993) surveyed third year medical students at a university and found that $57 \%$ of the respondents did not feel adequately prepared to interact with terminally ill patients. Studies such as these are important for exploring the concept of death anxiety among medical practitioners.

However, most of these studies are outdated and focus on physician death anxiety, not death anxiety as experienced by students. The more recent studies on the issue are limited in that they do not go into great depth on how the students themselves handle death experiences (Ratanawongsa et al. 2005; Rhodes-Kropf et al. 2005). It is also unclear as to whether the traditional medical values of prolonging life and averting death still remain core values. These recent studies on the topic have given limited attention to whether students still learn these values during medical school.

There is some literature that suggests changes have taken place in the medical curriculum surrounding end-of-life issues. Specifically, Rappaport and Witzke (1993) claim that education among medical students and doctors about death and dying dramatically increased in the 1970's and 1980's. In conjunction with the increase in patient autonomy over the last 20 years this may lead medical students to handle death experiences differently than students did 20 years ago. Yet, no studies were found that examine how the increase in patient autonomy may affect student experiences with death anxiety.

This thesis examines data from interviews with 20 students in their third or fourth year of medical school to explore these gaps in the literature. More specifically, this thesis aims to describe the various experiences that medical students have had with death 
during their medical training, how they handle patient death experiences and what they are being taught about death and dying in the medical school curriculum. The findings will shed insight on the medical socialization process specifically as it pertains to interacting with dying patients and managing death anxiety from the perspectives of the students themselves. 


\section{CHAPTER TWO - BACKGROUND AND SIGNIFICANCE}

The following section provides an overview of the medical socialization process that traditionally occurs during medical school, specifically as it pertains to experiences providing care to dying patients and coping with death anxiety. Next, I review recent literature on changes in medical settings that may lead to changes in medical students' experiences with dying patients. Finally, I conclude by reviewing a small body of recent literature on medical students' experiences with death during their medical training and how they handle such experiences. Limitations in the current research, as well as the significance of the proposed research, are presented.

\section{Medical Socialization around Death Issues}

Medical socialization consists of "an ongoing and tension-ridden series of encounters" in which lay values and attitudes are cast aside as medical "ways of seeing and feeling" become adopted by the student (Hafferty 2000:241-242). In doing so, students transform from ordinary lay individuals into physicians with 'extraordinary' abilities to manage issues surrounding health, illness, and healing. Among these values and attitudes, are those dealing with the meaning of patient death and how to cope with the loss of patients. In the early 1980s, some claimed that medical professionals "tend to view death as a sort of failure" (Fox 1981:45) and that death was viewed as "defeatism" amongst "physicians who view their responsibility as the prevention of death rather than the preservation of health and relief of suffering"(Friel 1982:70). Given this, physicians may have difficulties caring for dying patients and therefore also must learn how to cope with death when it happens. 
Socialization around managing patient death experiences takes place throughout the medical students' schooling beginning with the pre-clinical years, or years one and two of medical school, in which the student takes a gross anatomy course and learns the general science of medicine. It is in years three and four during which the student gains hands on experience interacting with patients during rotations, or clerkships in various departments. These rotations are supervised by attending physicians and provide the student with the opportunity to help care for patients. Years three and four are frequently referred to as the clinical years, as the student gains clinical experience in medicine while applying what they have learned in the classroom to actual patient cases.

During this medical training, in addition to learning about the hard sciences, medical students adopt "medical norms," which are expectations about how physicians should act, think, and feel (Weitz 2001:340). The socialization process during medical school transforms students into physicians as they experience both formal and informal means of learning not only scientific knowledge and technical skills, but values, norms and professional modes of conduct (Bury et al. 2004). During medical school, students are exposed to multiple social events, or "normative processes within which students internalize rules about the appropriateness of certain feelings, behaviors, and rationales within the life world of medicine" (Hafferty 2000:241). Students therefore learn what to value as they interact with other students and doctors not only in the formal settings of the classroom but in the informal settings of hospitals and doctor's offices. The socialization that occurs during anatomy lab has been previously explored through indepth qualitative analysis, (Hafferty 1988; 1991) in which it was found that students 
experienced anxiety and even nightmares because of anatomy lab. Expanding upon such research is necessary however, as it is clearly outdated.

A small number of studies have explored how medical socialization around death issues and how physicians cope with death anxiety affects patient care and doctor-patient communication. Dickinson and Pearson found that physicians who had taken less courses or no courses in death and dying were more likely to agree with the statement that, "treating dying patients is one of the most unpleasant aspects of my profession" (1980:172) than doctors who had more formal education on the topic of death and dying. They also found that doctor-patient interaction was affected when it came to discussing the patient's condition, as those who had taken a formal class on death and dying found it easier to discuss death with their patients. Dickinson and Pearson (1980) caution, however, that students who were more likely to take death education classes may have been more likely to be receptive to discussing death prior to starting their medical educations.

Values are also passed from physician to student through informal education. This is important, as Rappaport and Witzke found that one third of the students in their study had "never discussed with any attending physician how that physician dealt with terminally ill patients" (1993:164). What view of death physicians may pass on to students is therefore worth exploring, as it is a critical part of the physician socialization process.

In a more recent study, Larson and Yao suggest that physicians who are more connected to their patients, in terms of being "warm" and "friendly" $(2005: 1,100)$ are actually more effective when it comes to treating their patients. However, critics of this 
interpretation argue that detached concern, for example, helps to keep physicians from becoming "overwhelmed and paralyzed by a patient's pain and suffering" (Coulehan 1995:223). This may affect doctor-patient interaction in various ways. It may for instance, free physicians to make clear decisions about care without being overburdened by emotional attachment to the patient. On the other hand, it may lead patients to perceive their doctors as cold and distant.

Although these studies highlight the issues that medical students face as they are exposed to patient death, much of this literature is outdated. Further, the studies have not adequately taken into account changes that have taken place in the medical education over the last 20 years, nor have they examined how physicians' experiences with death may have changed given the continued increase in patient autonomy around end-of-life care issues. Such changes within the culture of medicine must be addressed in order to adequately explore the subject of death and dying and how medical students cope with and experience death anxiety.

What is particularly lacking in this literature is how the students themselves view and experience the socialization process, especially as it relates to death issues. This raises the question: how do students perceive what is taught to them about death and dying in medical school and how do they experience caring for dying patients? A key element of my research will include exploring how this socialization occurs and describing what students learn, both formally and informally, when it comes to death and dying. How students perceive they should handle death based upon their interactions with physicians they work with is important, as what they learn might affect their level of death anxiety. 


\section{The Medical Management of Death Anxiety}

Dickinson and Leming assert that "death per se has no meaning other than that which people give it" (2007:59). This is important, for our society has given death a negative meaning (Dickinson and Leming 2007: Hooyman and Kiyak 2008) leading many individuals to conceptualize death as something that is sad and something that we should fear. This can create a problem for medical personnel, who have been socialized to "prolong life and relieve suffering" as they may be uncomfortable with their role as care givers to dying patients (Dickinson and Leming 2007:156). As medical students interact with patients during their third and fourth year rotations, there is a great chance that they will be exposed to death. How then, do medical students manage the potential for emotional grief as they experience such deaths, and how do their coping mechanisms shape, if they do at all, their interactions with patients and families?

The discomfort that medical doctors may feel about death in general, including fear of their own mortality and that of their patients may affect how they interact with dying patients or the families of patients who die under their care. As medical students adopt "medical 'ways of seeing and feeling"' (Hafferty 2000:242) questions arise as to what this medical way of "feeling" actually entails. This is important, for it is the medical way of 'feeling' that may greatly affect, either negatively or positively, doctorpatient communication and interaction and the quality of care provided to dying patients. The role that the students experiences with death plays in the development of the medical students' identity, as a soon to be physician, cannot be understated. Hafferty points out that "situations involving death and dying function as rites of separation, distancing the 
students from their previous lay identities and permitting them to move to a new, more 'medical' persona" (1991:187).

In the context of modern medicine, the most common theme in doctor's coping with the possibility of losing patients is that of detached concern. Medical students are socialized to remain emotionally detached from patients as they attempt to find a balance between concern and compassion for their patients while resisting becoming so emotionally involved to the extent that it would be considered unprofessional (Weitz 2001; Bury et al. 2004). Additional issues arise when examining the socialization process of medical doctors. As Kleinman and Smith point out, "professionals are supposed to know more than their clients and to have personable, but not personal, relationships with them. Social distance between professional and client is expected" (1989:56). Keeping this distance and emotional detachment helps physicians to deal with death and dying.

There might, however, be other motives for keeping an emotional distance from one's patients. Coulehan (1995) for instance, claims that keeping an emotional distance from one's patients serves multiple functions. While such distance protects the physician from being overwhelmed by the patient's suffering it also simultaneously protects the patient. In this matter, the patient is protected as his or her physician is able to make objective decisions not influenced by feelings and emotions.

There are multiple ways in which medical students and doctors maintain this emotional distance from their patients. During rounds, for instance, students often informally learn to describe individuals under their care as "the patient" instead of by their name (Weitz 2001). According to Weitz, such language is used to perpetuate the 
idea that biological problems and disorders "can be separated from the person who experiences them" (2001:342). Ultimately in Western medicine, patients are seen as objects rather than people (Marcum 2008), thus perhaps enhancing the emotional detachment process. This enables medical students and doctors to keep an emotional distance from patients as they treat diseases and disorders, not the people who suffer from these illnesses.

\section{Medical Culture Changes around Death Issues}

Death anxiety among medical students has not been explored extensively in the $21^{\text {st }}$ century in the US. Although education about death and dying in medical schools began to increase in the 1970s and 80s, formal curriculum on the subject remained fairly absent even in the 90s (Rappaport and Witzk 1993). It was not until 1996 when organizations such as the Liaison Committee on Medical Education and the National Board of Medical Examiners began to mandate end-of-life care competencies into standardized examinations (Ratanawongsa et al. 2005). Formal curriculum on death and

dying remains limited in medical schools, as the vast majority of schools do not require students to take courses that examine the issue of death and dying (MacLeod 2001).

There are some changes, however, that are taking place concerning death and dying in the medical setting. Patient autonomy is one such change that is important because it incorporates legal and bioethical issues in terms of deciding how much care will be given and issues such as when to intervene to prolong life or when to let death occur naturally. As Dickinson and Leming (2007) point out, there has been a recent trend in Western society in which patients and families are demanding more control over their end-of-life care in terms of deciding what treatment they do or do not want to receive. As 
noted by Anspach (1993:166) "high-technology medical settings" lead to "a culture that rewards science, technology, teaching and learning, and that devalues interaction with patients, is coupled with a social structure that places barriers between physicians, patients, and parents" (1993:166). How such structured medicine may affect physician's acceptance and views of patient autonomy are worth exploring. Perhaps the acceptance of patient autonomy, or the patient's right to decide how he or she would like to die, affects medical students' and doctors' death anxiety in some way as they may be able to accept death more easily if they know it is a result of the patient's wishes. Given these changes, it is critical to examine how today's medical students experience death as compared to students 20 years ago.

Today there may be a unique difference in how the medical community teaches students to cope with and handle death as compared to several years ago. Perhaps the medical community's view of death is affected by the level of patient autonomy involved in making end-of-life care decisions. Medical students' views of patient autonomy will therefore be a critical issue to explore. The exploration of medical students' views of patient autonomy might produce a better understanding of why medical students experience death anxiety. There are few recent research studies that thoroughly examine death anxiety experiences of medical students and physicians.

\section{Recent Research on Death Anxiety}

While there are some studies that examine the issue of death anxiety among medical professionals, most are outdated, having been conducted in the 1980's. Also, most of the literature focuses on death anxiety amongst physicians, not medical students. More recently, however, Ratanawongsa et al. completed a qualitative study of third year 
medical students' exposure to dying patients and found that these students have experiences with patients who are dying that "affect their professional development" (2005:646). By this it is meant that students often have experiences with death during their clinical years that may affect how they will cope with death when they are licensed medical doctors. Their initial death experiences shape how they see themselves as professionals. After losing a patient, for instance, students may feel inadequate as practitioners, believing that they are not capable of truly helping people and they may begin to question their purpose and identity as a doctor.

Ratanawongsa et al. also found that a critical question is often raised when medical students find themselves working with the terminally ill, and that is, "How do I empathize with patients but maintain control over my emotions?" (2005:646). While their study discovered the existence of this question, it did not explore how students attempt to resolve the dilemma of empathizing yet maintaining control of their emotions. This is one such issue that I attempted to explore and answer during my study.

Another recent qualitative study conducted by Rhodes-Kropf et al. (2005) makes several claims about how students think they should react to and cope with the death of patients. Through the analysis of 32 interviews with medical students, the researchers found that two main messages are sent to students during their clinical rotations through informal curriculum. These messages are that "doctors should not have emotional reactions to death" as "death is a failure" and that "caring for the dying is not an important part of medicine" (Rhodes-Kropf 2005: 638). This is a distinctly different finding from Ratanawongsa et al.'s (2005) study in which emotional reactions to patient deaths were considered to be somewhat appropriate and in some instances even led to 
moments of silence and poetry readings. Ratanawongsa et al.'s (2005) qualitative interviews were conducted among medical students attending the University of California at San Francisco medical school, while those in the study of Rhodes-Kropf et al. (2005) attended unidentified medical schools in the Northeast. Perhaps the medical students are being socialized into different subcultures of medicine. This is something to take into consideration, as this study is being conducted amongst students in the Midwest region of the US.

These few recent studies are important as they highlight the issues that medical students face as they are exposed to patient death, yet most of the literature on the topic is outdated and more of the recent research does not take into account changes in the medical culture such as increasing patient autonomy.

There is recent literature that focuses on how doctors, though not medical students, cope with having to deal with terminally ill patients. MacLeod (2001) points out that doctors are socialized to adopt a technical attitude in which they are prevented from becoming emotionally involved with patients who are terminally ill. Though many see this as cold, it is important to note that, according to Donohoe, recent surveys have documented the "desires of practicing physicians for further training in caring for terminally ill patients and other topics related to death and dying" (2002:44). How physicians cope with dying patients is also important for it affects the end-of-life care that they deliver to their patients. Unfortunately, many physicians actually find that end-oflife care compromises the dignity of the dying patient and some would even go so far as to describe the effects of such care as disturbing (Del Vecchio Good et al. 2004). 
This is important, as physicians' attitudes towards death and dying may affect their interactions with their patients and their patients' families. Physicians who are better able to cope with death might be more empathetic towards families and patients while those who cannot cope as well might limit their interactions with patients and families and thus be perceived as callous or cold. It has also been found that sometimes physician emotion can have negative effects on patient care and even lead to "distress, disengagement, burnout, and poor judgment" among physicians (Williams, Wilson and Olsen 2005: 378). Although not an area to be explored in this study, it is therefore still important to take into consideration how physicians experience and cope with death and dying in their work as they constitute an important part of the socialization process that medical students experience. The students interact with physicians during their rotations and learn from their interactions how physicians should view and cope with death in addition to learning from the formal curriculum such as labs and lectures. Medical school curriculum thus presents the chance for students to learn through various formal and informal realms how they should view patient death.

\section{Limitations of Existing Research}

There are multiple gaps in the current research when it comes to medical students' death anxiety and how they interact with dying patients. The most obvious reason for this is the fact that much of the literature and research is outdated, as relatively few studies have been conducted on the issue in the $21^{\text {st }}$ century. Therefore, while the research articles cited above, such as Rappaport and Witzke (1993); Kane and Hogan (1985); and Dickinson and Pearson (1980), relate specifically to death anxiety among physicians, all are at least 16 years old with the oldest being nearly 30 years old. Clearly, 
more recent studies of the issue of death anxiety among medical students are needed. As patient autonomy in medicine has changed over the years, it is also possible that physicians' and medical students' attitudes have changed towards dying patients. Perhaps they are less or more hesitant to accept death than they were in the studies done in the 1980's and early 90's. Either way, this will remain an unexplored issue unless more recent research is conducted on the topic.

There are also several possible limitations within the research designs of the studies conducted just a few years ago concerning death anxiety among medical students that none of the studies addressed. For example, the article by Ratanawongsa et al. (2005), relates precisely to the topic of death experiences of medical students and was conducted by medical doctors themselves. Although it generates useful and important findings, the findings may be limited as no measures were taken to reduce possible biases that might occur when conducting insider research; that is when members of a social world study other members of their own social world (Rooney 2005). Without clear bias checks, it is possible that the students' responses may be skewed in terms of what they might say about their own fears and worries about interacting with dying patients and dealing with exposure to death as they may not feel comfortable sharing these issues with physicians whom they may perceive to be of higher power. This could limit the study's findings, as medical students might see these doctors as authority figures. This means they might perceive them as people whom they must 'save face' in front of and they might try to come across as confident for fear of being viewed as weak if they admit to any worries that they might actually have. 
Another problem with this recent research is that the authors state the interviews ranged anywhere from 15 to 60 minutes long. This leaves an uncertain amount of interviews as having been conducted in as little as 15 minutes. Since the researchers were aiming to conduct an in-depth qualitative research study, the fact that even just one interview may have only been 15 minutes long seems somewhat inappropriate as it will be impossible to collect rich data during such a short interview (Seidman 2006).

Ultimately, there are some limitations with the current research in the realm of death anxiety among medical students. Whether it is outdated data or issues of the unexamined role the researchers might play in influencing the respondents' answers, there is much room for improvement. The limitations within the existing research provide a unique opportunity to fill the gaps and address some of the limitations with my proposed study.

\section{Significance of the Proposed Research}

Up until the mid 1980's, very few studies had systematically explored death anxiety in physicians (Kane and Hogan 1985). This leaves the study of death anxiety among medical students as a relatively new development in medical sociology. The few studies that have been conducted in the $21^{\text {st }}$ century concerning medical students' experiences of patient loss, such as Rhodes-Kropf et al. (2005) and Ratanawongsa et al. (2005), are important. The descriptions of the students' experiences and coping strategies throughout these articles, however, remain relatively brief. An in-depth analysis of medical students' experiences and coping strategies is therefore still needed.

It is important to examine issues such as these that affect how medical students experience professional socialization as they become medical doctors, which may 
influence how they view death and therefore how they interact with dying patients and/or the family's of patients who are dying or deceased. Exploring the socialization process that occurs during medical school may give us better insight as to how medical students cope with death and relate to their dying patients which is important for various reasons. Not only might this help the students' understand their own experiences but it may help them to find ways in which they can better connect with patients and ultimately improve care.

The ultimate goal of this study is therefore to better understand how medical students experience death as they complete their rotations in which they interact with patients under the supervision of attending physicians. A better understanding of what medical students go through as they attempt to become doctors can help us find ways to better educate them in the realm of death and dying, and may be used to enhance doctor patient communication. The end results of this research may not only be beneficial to the medical community, but should be useful in expanding the knowledge of medical sociology in the realm of academia as well. 


\section{CHAPTER THREE - METHODS \\ Overview}

This is a qualitative study in which I conducted semi-structured in-depth interviews to better understand medical students' experiences with the death of patients. A symbolic interactionist perspective guided the research design. Symbolic interactionism involves the following premises: humans' behavior is based on the meanings they give to certain objects and events, that social interaction supports those meanings, and that the meanings themselves are created through a process of interpretation (Esterberg 2002:15). Essentially, symbolic interactionists are interested in studying the symbolic nature of social interaction to explore how social interaction creates meaning and promotes socialization, thus helping individuals create their self identities (Schutt 2006). Since this perspective relies on how individuals interpret events and give meaning to them, it was reasonable to collect data through interviews, as they gave rich descriptions of how medical students cope with death as they become doctors. Interviews are especially useful because they allow for understanding the meaning of patient death experiences from the perspectives of the students themselves.

\section{Reflexivity Concerns}

There were a few issues of reflexivity in my proposed study. Reflexivity refers to the researcher's ability to scrutinize his or her research and how the decisions and interpretations that the researcher makes are influenced by his or her own interests and assumptions (Charmaz 2006). One such issue concerns why I am interested in studying death anxiety among medical students. While I have not experienced the loss of close friends or immediate family members, I have witnessed people's reactions to death, including youth suicides and natural causes in adulthood, as I went through middle school 
and high school. More recently a close friend lost her father, who was a physician, to cancer. Being exposed to these deaths has peaked an interest that has led me to want to study how people in general cope with death, as I saw some react to the deaths with grief and others silence, myself included. Studying how medical students, however, react to death creates a unique opportunity to not only explore how this particular segment of our society copes with death, but may increase understanding of how doctors interact with families of patients who have died.

Dickinson and Leming (2007) argue that we live in a society where death is considered a taboo topic and is therefore not frequently discussed. The issue of reflexivity comes up because I want to explore this taboo topic as I am more willing to discuss it than most other people probably are. Since I am more open to exploring death in general, I might interpret the medical students' thoughts about death and dying inappropriately. I might for instance, interpret their possible lack of discussion with fellow students on the topic as a coping mechanism for not having to deal with death while in reality it may be that they simply do not think much about death.

The issue of my own personal beliefs as to how doctors should relate to patients may also play a role in my interpretation of the data. I believe, for instance, that detached concern is somewhat necessary in the culture of medicine. If doctors truly empathize with, and relate to every patient they interact with, they may run the risk of becoming burnt out. Also, the emotional distress they might feel when they see patients suffering might be overwhelming. Thus, I believe detached concern is appropriate and needed in medicine. This may affect how I interpret the data, however. For instance, I might regard the self-reported behavior of a medical student to be an attempt to use detached 
concern, which I would consider appropriate. However, their behavior might actually just represent a cold medical student who cannot relate to patients. I realize that I need to be reflexive in this situation, however, which means that I must develop an understanding of how my beliefs and attitudes are shaping the research that I wish to conduct in terms of objectivity (Esterberg 2002). I believe I was be able to do this, as throughout this study I attempted to remain open to different interpretations of the data I collected although I realize complete objectivity is simply not always possible.

\section{Sample and Recruitment}

My sample consisted of third and fourth year medical students from a large Midwestern medical school. It was important that they be at least third year for multiple reasons. Not only does their being enrolled in the third year mean that important emotional socialization aspects have already been experienced, such as interacting with a cadaver but it means that they have had the chance to interact with patients. While not all students I interviewed had interaction with dying patients in a palliative care setting, this is okay, for I was also interested in exploring how students cope with death that is unexpected and sudden, which could happen on any rotation. I also explored their general attitudes towards patient deaths, which included exploring their opinions on what is a good death as well as physician-assisted suicide. A key part of my study consisted of exploring what death anxiety students do have, even prior to experiencing the death of a patient. Therefore, while it would have been ideal that all have been exposed to at least one patient death, this was not a necessity for my sample.

I recruited medical students through email advertisement. In terms of email recruitment I relied most heavily on the use of medical student listservs as they had the 
potential to reach a large number of medical students. First, I recruited through the medical student event listserv that is received by third and fourth year medical students. A third year medical student, who was introduced to me through my advisor, agreed to circulate my recruitment flyer to this listserv. In addition, I contacted another third year medical student who serves on the Medical Student Council and he agreed to circulate my recruitment flyer to third and fourth year students who have completed palliative care classes. I was able to recruit 20 students through these methods for my study. The students ranged in age from 24 to 29 , nine were male and eleven were female, and nine were $3^{\text {rd }}$ year and eleven were $4^{\text {th }}$ year students. I compensated each student with a $\$ 25$ visa gift card for their time.

\section{Research Instruments}

I conducted private in-depth semi structured interviews that lasted from 45 to 60 minutes. In addition to audio taping the interviews with the students' consent, I also took notes throughout the interview. These interviews created a unique opportunity for me to explore the students' experiences with death as they were able to tell stories and describe in detail what they experienced when losing patients and what fears or concerns they might have when it comes to death and dying. Semi-structured interviews therefore worked the best when it came to collecting data. This is because at the root of in-depth interviewing is the interest in attempting to understand the experiences that other people live through and the meanings that they attribute to such experiences (Seidman 2006).

Interested students contacted me for an interview via email, as that was the only contact information I posted on the recruitment flyer. Upon initial contact, I discussed with them what day or time would work best for them and then scheduled them for an 
interview. The interviews either took place at the Sussman library or university library where private rooms were available unless the participant desired that the interview take place at a location of their choice. Some participants did choose to meet at locations other than the libraries such as Starbucks, the medical student center on campus and other local coffee houses.

The interviews began after I explained to the participant the research goals of the study. I also compensated them for their time with the gift card after they read and signed an informed consent form. I started by asking the students a few background and demographic questions regarding age, race and ethnicity and level of medical schooling that had thus far been completed. This was done in an effort to help the interviewee relax, as they became use to the presence of the digital audio recorder. After the demographic questions, I moved on to a set of main questions, consisting of probes and follow up questions. These questions began with the aspects of what gross anatomy lab was like for the participant and then ranged from asking them to describe what they experienced when they lost their first patient to how working in medicine has affected how they feel about their own mortality. I also asked about attitudes towards various kinds of death such as what makes a good death and physician-assisted suicide. Upon completion of the interview, I thanked the participants again for their time and always ended our interview by asking if they had any questions for me (See the appendix for the complete interview guide that was used).

\section{Data Analysis}

I did not complete any in-depth analysis of the interview data until I had completed all the interviews as Seidman (2006) suggests. I did however, continue to 
draft new and revise old questions based upon what I learned from interviewees and began preliminary analyses of five interviews prior to completing data collection. During the analyses stage, grounded theory analyses techniques of line-by-line coding were used to keep the analyses close to the data; this helps minimize researcher biases and helps insure that the findings represent the students' experiences (Charmaz 2006). I used the software NVIVO 8 to organize my data as I coded the interviews into various sections and themes. In addition, I wrote memos about major themes based on what was most salient among the line-by-line codes. The memos became the basis of my findings chapters.

\section{Research Challenges and Risks}

There were a few challenges that I encountered in my study. The most obvious was that medical students are incredibly busy as they must continue studying while completing their third and fourth year rotations. To try and compensate for this limitation I offered a \$25 visa gift card which appeared to be a reasonable way to show the students that I was taking their experiences seriously and that I truly did appreciate the time they were willing to take out of their busy schedules for an interview. Also, I offered to be available at any time which might have been convenient for the student, allowing them to choose the time and location of the interview.

Another challenge that I encountered was that of developing rapport. I do not personally know any medical students and have never experienced the emotional strains endured during medical school nor do I know what it is like to suffer the loss of a patient. For this reason, the medical students may have viewed me as a complete outsider who could not fully understand their experiences. This may have initially influenced the way 
they responded to my questions. This is because a certain level of trust should be first established to gain their confidence that I was a serious researcher.

There were relatively few risks associated with my study. The only risk that was most obvious is that the medical students who participate might experience emotional discomfort or sadness when discussing their death experiences as medical students. None of the students, however, became emotional during the interviews and all of the students completed the interviews.

There were no associated risks with confidentiality, as I was the only one conducting and transcribing the interviews. I used pseudonyms for any names or locations that the students mentioned in an attempt to limit the ability of anyone from the general public to recognize the students. In addition to replacing the students' names with pseudonyms, in some cases patient descriptors have also been changed. Also, the informed consent forms were kept in a private, secured location as they were the only way the students could be identified, as the audio files were destroyed upon completion of transcription. All of these steps were taken to limit the potential risks associated with participant well being and confidentiality. In addition, the study received IRB approval from the University research ethics review board.

\section{Conclusion and Findings Overview}

The existing research concerning death anxiety among medical students is limited for various reasons. While the most obvious being that much of it is outdated, the recent research conducted on the topic fails to meet many of the criteria that make social research reliable and valid. Also, while the literature tends to focus on the idea that doctors are socialized to see death as failure, it fails to take into account any changing 
attitudes among physicians and medical students regarding death that may have occurred over the past few decades. Lastly, death anxiety among medical students is an interesting topic within medical sociology that is worthy of more study as it relates to how doctors and students view death and dying in the medical setting.

Several interesting themes emerged on the topic and are presented in three separate findings chapters. First, I present findings surrounding the students' experiences in anatomy lab. The next chapter explores the students' experiences with patient deaths. Finally, in the last findings chapter, I examine findings surrounding the students' attitudes towards several kinds of patients' death. I conclude the thesis in a final chapter that summarizes the main findings of the thesis, their significance, and implications for future research. 


\section{CHAPTER FOUR - GROSS ANATOMY LAB EXPERIENCES Introduction}

Often described as a rite of passage, gross anatomy lab is a critical component of medical school curriculum. In signifying that one is on the path to becoming a medical doctor, anatomy lab represents one of the first steps in the socialization of the medical student into their profession. For some students gross anatomy lab may also represent their first experiences interacting with a cadaver. Such exposure to a deceased human may often entail reflecting on mortality, as it is a clear representation of death. For these reasons, exploring the medical students' experiences of anatomy lab is important in order to gain a better understanding of how they experience the beginning stage of socialization into their profession.

The findings here suggest that anatomy lab may produce some level of emotional and even physical discomfort in students as they find themselves interacting with a dead body, which usually is the only time such work is ever expected of them. In addition, the students' experiences suggest a "culture of silence" may exist around publically expressing such discomfort. In response to the discomfort and silence that existed, students often enacted coping strategies to manage their discomfort. The majority of medical students in this study did not have any experience with cadavers until the first year of medical school during gross anatomy lab. Three students however, did enroll in anatomy courses as undergraduates and one also witnessed several autopsies. This represents a unique contrast to the experiences of medical students explored in previous research (Finkelstein and Mathers 1990; Dinsmore, Daugherty and Zeitz 2001). The findings in this section elaborate on three themes related to anatomy lab experiences, (I) 
experiences with anatomy lab as an undergraduate; (II) experiences with anatomy lab as a medical student; and (III) coping strategies used to manage discomfort in anatomy lab.

\section{$\underline{\text { I. Experiencing Anatomy Lab as an Undergraduate Student }}$}

During undergraduate anatomy the students themselves did not take part in dissection. Being in the presence of a deceased human, however, had an obvious effect on most of the students. Two of the three students who took undergraduate anatomy experienced discomfort and the third expressed feeling emotionally detached. In addition, taking anatomy lab as an undergraduate may also represent a unique change in the traditional way in which students are socialized while becoming physicians, as they are exposed to a cadaver before their medical training actually begins.

One such student who participated in anatomy lab before medical school claimed that she was initially opposed to using cadavers, but enrolled in the course because she needed a lab science to graduate. Although she does not give a clear reason why, it appears that her initial discomfort felt when working with a cadaver as an undergraduate was alleviated by the time she began to work with a cadaver her first semester of medical school. She explains:

I needed a lab science to graduate with anthropology ... and was totally opposed to it because I had just spent a year in Idaho and I lived next to the Nez Perce Indian Reservation and had Native American friends out there and their conception of what should happen to a dead body is very much against having a cadaver around. So I was very against it in undergrad and then when we came back to it in our first semester of anatomy, I don't know what happened but all of those feelings, like intense feelings that this isn't right, you know, that we were disrupting the spirits, I wasn't bothered by it anymore (Alexandra). 
In Alexandra's experiences, it may have been the case that the initial exposure to a cadaver helped ease the "intense feelings" that working with cadavers "isn't right" by the time she was exposed to a cadaver during medical school.

Two other students who experienced anatomy lab as undergraduates described their experiences by using words that pertained to their emotions. In particular, for Dennis, there was a level of emotional detachment. In this case, it seems as though the student did not find it emotionally difficult, but instead simply felt emotionally detached from the cadaver. He claimed, "It felt very detached from anything, anything emotional or anything I would feel emotionally attached to." This differs from the description provided by Mary, who had a difficult time with anatomy lab as an undergraduate. Mary described her undergraduate anatomy course as "startling emotionally" and stated that "to see the body...was disturbing."

As will be shown below, the emotional issues that the students above experienced as undergraduates were not vastly different from those that other medical students experienced during their first semester of anatomy lab, as for most of them it was their first exposure to a cadaver.

\section{$\underline{\text { II. Experiencing Anatomy Lab as a Medical Student }}$}

Although working with a cadaver as an undergraduate may have had some affect on how these students felt during their first anatomy course in medical school, there is an important difference between undergraduate and medical school anatomy lab courses. It is in the latter that the students are not only exposed to deceased persons but actually take part in the dissections of the bodies. The majority of the medical students experienced a general sense of discomfort although others frequently made comments that specifically 
referred to experiencing more discomfort when making the first incisions or when dissecting the heads and faces of their cadavers. Some students also provided descriptions that seemed to imply that there is a "culture of silence" around expressing such discomfort to others.

\section{Experiencing Discomfort}

The majority of students experienced some kind of emotional discomfort during the initial phase of their experiences in the lab in medical school. Although some students refrained from making their nervousness or uneasiness known to others, through the descriptions they provided, it is obvious that they did indeed experience discomfort during anatomy lab. Luke, for instance, frequently made reference to how initially working with a cadaver was "spooky." While such language is vague, it nonetheless may simply represent Luke's level of discomfort in working with a cadaver. The following passage illustrates Luke's experience:

[Seeing the cadaver for the first time] was pretty spooky. It was a body but it didn't even really seem like a body because it was so dark and grey and preserved. But we did the shaving and we had an orientation day where they left [the bodies] all exposed and had us shave the body just to kind of get familiar with it and get the spooks out of us. There were eight bodies on this table in this little room and it was kind of spooky. But it wasn't too bad, but once I got out I was like, "Woah, that was weird."

Luke refrains from using terminology that implies anxiety or intense discomfort and instead spoke of lab as being "spooky" and "weird." Other students, however, made explicit statements that seem to show they experienced some level of anxiety. Madison was one student who clearly had an anxious emotional reaction to being exposed to the cadaver for the first time as she stated:

The cadaver cases were open but they were still covered with a sheet. And a girl that I had just become friends with and myself, our hearts were 
racing and we just had so much anxiety about seeing the cadaver itself. There was another guy in our group that wanted to uncover it and start right away. And he uncovered the arm. And that's one of the most human looking parts of the body that you really see on the cadaver, the hands, the face. [So] that just freaked us out even more, so we put the sheet back over it.

As the experiences of the medical students described above illustrate, there may be general discomfort and awkwardness felt while working with the body. Levels of discomfort may vary, however, as some students went into more detail concerning how they felt about working with cadavers. These students frequently used language and provided descriptions that were much more intense than those of the students above.

Ava, for example, had a very difficult time during anatomy lab. Ava represents a case in which gross anatomy lab was the first time she was ever exposed to a deceased human. She made this clear when she stated, "I'd never had any death experiences [with] a close family member before. I'd never attended a funeral before. So [anatomy lab] was very dramatic for me." Ava perceived the dissection of the human body in her anatomy lab to be "brutal" and spoke of feeling uncomfortable when participating in it:

The body looked like a rubbery model. It didn't look like a human body at all. [But] when we had to dissect the body, I kind of had to go off for a moment because [I] was very uncomfortable. [The dissection] was very brutal. You dissect every single piece of the body, even the eye.

Other students also described what they felt concerning the dissection process.

Charles spoke of experiencing anxiety as he appeared to be nervous about interacting with a cadaver on such an intimate level at which dissection takes place. It appears that in Charles' case the anxiety he felt stemmed from his understanding that he was going to be dissecting the body (rather than merely being in the presence of a body) as to him, the 
dissection entailed working with a deceased person on a rather intimate level. Charles explained:

I think for me I was kind of nervous. Filled with a little anxiety. This was the first time I had ever encountered a cadaver, a dead body per se and then knowing as a medical student what I would be doing with it. What our class would be doing with each of our donors kind of exploring them to the most intimate detail. I mean you know it's kind of cutting them open. So I was pretty anxious.

As the discomfort felt by most of the medical students above clearly varied, for at least one student, the discomfort appears to be more severe than the others. Meredith spoke of not feeling comfortable with dissection and even wanting to find a way to simulate anatomy lab so cadavers will not have to be used. Although this deviates from the stories of the other medical students, as no one else discussed wanting to simulate anatomy lab in order to avoid having to use cadavers, it is a telling example of how uncomfortable anatomy lab may make some students feel. Below Meredith describes her feelings and attitude towards anatomy lab:

So anatomy lab was the first time I ever interacted with a cadaver and I can remember that I was not looking forward to it and still even now, I'm not comfortable with the idea of doing dissection on cadavers. Just thinking that cadavers used to be people and that basically we're dissecting this person, it just doesn't sit well with me...I basically don't feel like its right that that's how we learn anatomy. I've talked with some medical students about how I wish there were some way they could simulate the cadaver lab without using cadavers.

While the experiences of the students discussed above exemplify the general anxiety and discomfort often felt by students who are taking anatomy lab, it was not unusual for students to express a greater level of uneasiness when they made their first incisions as well as during the dissection of the cadaver's head and face. 
Jack and Michelle both mentioned experiencing some level of discomfort upon making the first incisions. In Jack's case, however, it appears that the discomfort he felt in performing dissections was displaced as he rationalized his experience as something that was just a "rite of passage" for all medical students. He explained what it was like to see the cadaver he worked with for the first time and what he felt prior to beginning the initial dissections:

I walked in and a huge six-foot guy was my specimen. [And] just to see that [he] was an actual human being really struck home. It was kind of nerve racking in the beginning. I was actually given the razor at the beginning, the scalpel to make the first incision on the body and that was difficult. It was strange and kind of an out of body experience for me, but after you make the first few cuts and you see that everyone's kind of nervous, you kind of understand that that's just a rite of passage into med school.

Similar to the emotional experience of Jack, Michelle referred to making the initial cuts to the cadaver as "difficult." Even though she acknowledged that the cadaver could not feel pain, she still seemed bothered by the task of making the first incisions:

At the beginning, the body's very intact and you know (sigh) it was really, really hard to make the first cuts on the skin even though there wasn't any pain issue. It wasn't like when you're giving a shot and [a] little kid's screaming. [But] it was so difficult.

Some students described dissecting the head and the face in terms that reflect these particular dissections as more difficult than any other. One student even questioned whether such dissections take place at all centers (or medical campuses) throughout the state because to her and her classmates the dissection of the cadaver's head did not seem "right." She used strong language when referring to the dissection as "the worst thing [she's] ever had to do," acknowledging the discomfort that she felt during the dissection. Her questioning as to whether or not they do such dissections at all centers is important as 
it reflects her reality in which the dissection is seen as so extreme it must be out of the ordinary and not something that all anatomy students experience. Below she describes how she felt during the dissection of her cadaver's head:

The toughest part for me was, I don't know if they do this everywhere, but at our center they make you cut the head off and then cut it in half. I did not like that at all. I almost said I may not do this. I don't know if that was an option, but I was seriously considering just refusing to do it....I remember sitting there holding half of the head and this other girl's holding the other half and this guy's using a hand saw. I remember holding the head thinking like, this is the worst thing that I've ever had to do and I was just in a very sad place right then... And we actually did have conversations among us like, do all the centers do this? Because we thought it wasn't right (Susan).

Similar to Susan, Josh also used strong language to describe the process of dissecting the head, referring to it as "traumatic." The uneasiness that Josh felt while dissecting the head is clear in the following description that he gave of the process:

It came down to me having to dissect the skull which is where you cut straight down from the back. And that was traumatic. Because you don't use a bone saw, you actually use a hand saw, and you're standing there cutting a person's head in half. And that stuck with me for a couple weeks and I thought about it, and I was like, did I really do that? Was that really a person that I just cut their head in half?

Students also had a difficult time with the dissection of the head because up until that point it appears that they were able to dehumanize the cadaver by simply avoiding thinking of it as a person. Since the face is a very personal part of the human body, it is understandable as to why some of the students mentioned that dissection became more difficult once they reached the cadaver's face. The description of dissection up until the face provided by Dylan illustrates this as he commented:

Once we were able to cut open and actually see the musculature, the veins, the arteries and all those things it got very easy. Until we got to the face. Then we had to turn the cadaver over and we saw her face for the first time. Because originally their faces were covered with a plastic bag. And 
then it became hard again. Very hard...It wasn't really until we had to turn their bodies over and we had to look at their faces that people really remember, oh this is actually a person.

\section{Not Expressing Discomfort}

For some of the students, anatomy lab was embedded in a culture of silence, in which not expressing discomfort was the norm. As the students' quotes below suggest, this may stem from the competitive nature of medical school and the desire of students to be able to present themselves in a professional manner and to avoid looking emotionally vulnerable or weak.

Some students did not openly discuss discomfort with others even though they acknowledged feeling uncomfortable or finding their tasks of dissecting the cadaver to be bothersome. For instance, Ava stated, “We didn't talk much about our feelings...nobody seemed to encourage the topic. Nobody brought it up, so it just kind of headed along the way." Similarly Madison, who clearly experienced anxiety nonetheless felt the need to hide such emotion as she stated "Being a girl, and [it] being my first year, I didn't want to be the person who looked like they couldn't handle it." Such a statement reveals that anatomy lab is something that can be difficult for students as they must be able to "handle it.” Likewise, Alexandra, said:

I think people are uncomfortable, I mean I'm not going to say it's not uncomfortable because it is uncomfortable. I mean it's strange. And it doesn't feel natural and it smells really bad too from the chemicals and the decomposing bodies but nobody ever came out and said "Wow, I really think this is awkward." I mean yeah, I think we did feel uncomfortable but at the same time nobody openly was ever upset about it.

These students clearly felt awkward during anatomy lab, but made it clear that such awkwardness is not something that is frequently or openly acknowledged by students. 
Derrick also had similar experiences, as he too seemed to experience discomfort.

Although he never states this, he speaks of not wanting to "freak out" and said that "there's a little bit of pressure on you to try to be cool." Such wording may reflect the desire to not let any worries or anxieties show while working with a cadaver. It also appears that in Derrick's case the competition of medical school helped alleviate the discomfort felt in anatomy lab as he explained:

They're all leathery skinned and everything, but at the same time the awkwardness, you balance that with the fact that you're in a group with five other people you don't know and you're told that med school should be competitive. You're all trying to get good grades and so you don't want to freak out...then you've got a handful of instructors in the course and a handful of teaching assistants. They're there to help you but that first day they're also interested in funny stories, like who's going to pass out...so there's a little bit of pressure on you to try to be cool.

Derrick's description implies that even if he felt some kind of uneasiness or discomfort he most likely did not feel comfortable expressing such feelings in light of the competitive atmosphere of med school.

Just as Derrick spoke of wanting to keep "cool", Josh also appeared to be hiding some level of an emotional reaction to dissection in light of competition as he explained:

There's that persistent theme of competition [in] medical school, [so I just] described [the experience of dissecting the head] as intense. So as to not say, "Oh, it was traumatic," or "Oh, it bothered me," but I did describe it as intense.

In a similar manner, Madison, explains why she was eager to not appear to be "too anxious":

I think there's also a part of you that thinks, "If I can't handle this, am I really going to be able to handle being a doctor and sitting through surgeries, doing this on real people?" So that's always kind of in the back 
of your mind. I didn't want to be the person who was too anxious because I thought I really need to be able to handle this if I'm going to move on to the next part of medical school.

A part of the culture of silence described above may be in part credited to the need for students to hide anxiety in order to appear to be prepared to work in medicine. While the dissection of the cadaver may invoke intense discomfort, it is only a piece of the process that medical students must go through in order to become physicians. The need to appear to be strong and independent, especially in a competitive atmosphere, may possibly motivate some students to not discuss their emotions with others.

\section{Coping with Discomfort in Anatomy Lab}

Given the discomfort described by the medical students above, as well as the general culture of silence that led many students to not publicly express their discomfort, various strategies of coping with having to interact with a cadaver arose. These included the medical students' dehumanizing or humanizing the cadaver. While such concepts seem to conflict with one another, some students simultaneously used both strategies.

\section{Dehumanizing the Cadaver}

Dehumanizing the cadaver was common and appears to help students deal with having to dissect the body. In the previous section students spoke of a greater level of discomfort that was felt when they had to dissect the head and face, perhaps the most personal part of the cadavers. The presence of greater anxiety during this dissection may indicate that prior to reaching the face students were able to dehumanize the cadavers. Take for instance the story of Luke, who spoke of how the students dissected parts of the cadaver and "bagged" the other parts they were not working on. According to Luke, this helped him to view the cadaver as a body and not a person. In his case, working with one 
part of the body at a time while the rest remained out of sight seemed to help Luke become comfortable with the dissections:

We bagged all the extremities and just worked on one part of the body at a time. We kept all the parts of the body in a bucket. It was just like working on a little piece at a time. Keeping the other parts bagged up really helped because it didn't feel so crude.

Students also commented on the way the appearance of the cadaver changed throughout the semester. As the initial dissections may have been difficult for some, it appears that once the cadavers began to physically change it may have become emotionally easier for students to participate in lab, because the cadaver looked less like a human. Michelle, who initially experienced great discomfort in making the first incisions stated, "As the semester goes on and you've gone through the systems, the body doesn't really look like a person anymore." Madison is another student who appeared to dehumanize the body as she commented, "We pretty much waited until the last minute to uncover [the body] but once you start doing the actual dissection itself I think it kind of takes the human qualities out of it." Rachel's comments also illustrate the possibility that intense immersion in anatomy lab helped dehumanize the cadaver, as students spend several hours a week working with the body. She explained:

In some senses you get desensitized because you're there ten to fifteen hours a week with this body. [But] I don't really mean you view it as an object. I guess I just mean that you've kind of processed it and you've come to the point where you thought about how this was a human life, you've thought about the sacrifice that this person gave by giving their body and now what you really need to be learning is the medicine.

In her case, the time she spent working with the body desensitized her to the fact that she was working with a deceased person, allowing her to truly appreciate the "sacrifice" that the donor made so she could study medicine. 
For these students there appears to have been a process of dehumanization that took place during their gross anatomy labs. Dehumanizing the cadaver most likely helps students to cope with having to perform such intimate dissections on it and allows them to focus on the science that they learn through participating in the dissection process. Instead of viewing the cadaver as a whole body, as mentioned above, some of the students were able to cope with participating in dissection because the cadaver simply did not look human.

\section{Humanizing the Cadaver}

Interestingly, it also appears that some students also humanized the cadavers by naming them and referring to them as patients instead of cadavers while some even created storylines about them. Dylan, for instance, explained that he and his classmates wanted to have some sort of connection with the cadaver because of the sacrifice the donor had made as he commented:

We opened up the case and there she was. And the first thing we did oddly enough was name her. We wanted to have some sort of connection with this person because this person had basically given us this gift of her body so that we could learn. And so we named her.

Acknowledging that the cadaver was at one time a human also seemed to help students maintain respect for the sacrifices that the individuals made in donating their bodies to science. Respecting such sacrifice was also apparent when some students spoke of ceremonies that take place at the end of anatomy labs which are held to thank the family members of the donors. At these ceremonies the students are apparently given the opportunity to thank the family's of the donors. When I questioned Derrick about such ceremonies he commented: 
I think you're welcome to attend but they'll take like a handful [of students] and have them prepare either some kind of poem or some kind of speech to the family members of the donors and... [If I had been asked to do that] I would have... I don't know that anyone could possibly refuse because you know that the donors and their family did make a contribution to your education at no cost to you. And it's just nice to have some way of saying thank you; you'd be a real jerk if you didn't.

Derrick's words imply that he perceives his donor to have made a valuable contribution to his education that is worthy of respect, which is something that is shown at these ceremonies. Dylan was another student who commented on a ceremony that was held at the end of his anatomy course and stated that "It's very sacred...because it is a valuable sacrifice that these people made for us." Alexandra and Mary were two other students who also spoke of ceremonies. Although Alexandra believed that "some people didn't take it as seriously as others," she referred to it as something that she thought of as a "good thing." Mary also spoke of a ceremony during which her class held a candle light vigil at which the students were able to thank the family's of the donors.

The ceremonies that the students above spoke of may reflect a humanization of the cadaver, as they entail that students acknowledge that at one time the cadavers were living beings with various relationships. Since these ceremonies take place after anatomy lab is over, attending these ceremonies is most likely not necessarily a coping mechanism used to handle interacting with and dissecting a cadaver, but perhaps just a way for those involved to remember the life of the cadaver and show that they truly do appreciate the individual's donation.

\section{Simultaneously Humanizing and Dehumanizing the Cadaver}

Some of the statements made by the medical students were difficult to separate in terms of whether or not they were humanizing the cadavers (such as by giving them 
names and storylines) or dehumanizing them (such as by not viewing them as deceased humans, covering parts with bags, and emphasizing learning the science, etc.). In some cases, the students gave descriptions of their experiences that seemed to do both simultaneously. Take for instance the comment of Josh below, which seems to illustrate simultaneous humanization and dehumanization of the cadaver:

The very first time we walked into the anatomy lab I wasn't expecting us to see the cadavers [but] it literally was the very first day that we showed up that we ended up seeing our patients. Our first patients are what they call them. And they start them out laying prone so that they're face down and you start out working on their back and doing the anatomy of the back. So it kind of dehumanizes them from that standpoint [because] you don't start out with the face and you're looking at some recently deceased person's face.

Calling the cadaver a patient brings it to life and gives it a symbolic place in the realm of anatomy lab. In life patients are living beings that medical students are being trained to care for. At the same time, however, Josh states that by starting the dissection on the back, the "patients" are dehumanized as it allows students to avoid looking at the face, which is a much more human and personal part of the cadaver.

Due to the rapid pace of anatomy dissection and intense immersion in the class some students may have unintentionally dehumanized the cadaver. At the same time of this dehumanization, however, some students kept a human connection to the cadaver.

Take for instance the experience of Janet who commented:

I thought it was a great experience, you know you kind of get over the human part of the cadaver within the first week or two. The first day that we met our cadaver, he became a person to us. We had a name for him, we [created] storylines and [wondered] about where his family was but it almost felt like we weren't cutting on a real person [because] by the third day he just is totally macerated, cut up. 
Janet's comments seem to imply that although she and her classmates humanized the cadaver by giving him a name and even wondering where his family was, such human aspects quickly gave way to the fact that the physical appearance of the body rapidly changed over a short time period, allowing Janet to dehumanize the cadaver.

\section{Conclusion}

Most of the students experienced some level of discomfort during anatomy lab. Although a few did take a general anatomy lab as undergraduates, it was not until they enrolled in anatomy lab as medical students when they were required to do actual dissections on the cadaver. Interacting with a deceased person on such an intimate level led most of the students interviewed to experience various emotions during their lab sessions. As found in previous research, such anxiety is not abnormal (Hafferty 1991). Also, as explored above, there is often a culture of silence that prevents students from openly acknowledging such discomfort. For students to be able to continue on with their medical training and enter the role of the M.D., they must find a way to cope with the discomfort they experience during anatomy lab. Dehumanizing and humanizing the cadaver are two of the ways in which students do this. Further research is needed, however, to explore more thoroughly the culture of silence that the medical students find themselves in and how they cope with the discomfort they feel during anatomy lab. 


\section{CHAPTER FIVE - PATIENT DEATH EXPERIENCES Introduction}

During the clinical years of medical school students interact with patients as they complete monthly rotations in various specialties. During such rotations students begin to apply what they have learned in the pre-clinical years as they join medical teams consisting of interns, residents and attending physicians that care for patients. The clinical years therefore represent an important transition in the socialization of medical students into the medical profession. While it may be an exciting time for students, as they are able to interact with patients, it may also be a time in which they experience stress and anxiety as they are exposed to intense case loads and long work hours. In addition to such extreme work conditions, students may experience patient deaths which may affect them on various emotional levels. It is therefore important to explore how students experience the deaths of patients and the ways in which they manage distress and cope with such loss.

Some of the deaths described in this chapter also illustrate important themes that arose during this research such as the human element of medicine and the difficulty experienced in not only interacting with dying patients but also their families. The human element of medicine can be thought of as one concept with two components. The first being that uncertainty and risk are part of practicing medicine. Even physicians who are competent and experienced may make decisions that affect the patient's care in a negative way, although not intentionally. The second component is that there may be a chance for human error to influence the patient's outcome as new procedures are implemented or physicians are performing procedures for the first time. Although it was

rare for students to give descriptions of patient deaths that shed light on the human side of 
medicine, it appears that every student who lost patients because of human decisions and possible human error were emotionally distressed by the losses.

Another theme that arose during the interviews was the difficulty that some students experienced when talking and interacting with the family members of dying patients. This was understandable, as sometimes the students' patients were incapacitated and unaware of what was actually happening to them. Also, after the death of a patient the family may be emotionally distraught or find the loss of their loved one difficult to accept. Some students empathized with families prior to and after the deaths of patients, and therefore found it emotionally challenging to interact with them. The possibility that the interactions may be negative, as sometimes families may be unhappy with decisions made by physicians during care, could also influence whether or not students perceive interacting with families to be difficult.

The students in this study also had various death experiences ranging from the anticipated loss of elderly patients to the sudden and unexpected death of an ill child. A handful of these experiences are described below in the section on descriptions of patient deaths, which are broken down into adult deaths and pediatric deaths. The students also described ways that they coped with such deaths and the various emotions they experienced. These coping strategies included those which seem to be acceptable within medical culture such as talking, carrying on with their work, and participating in rituals after infant deaths, and those which appear to be more personal and tend to take place outside of hospitals, such as crying and turning to religion. These findings are further described below in two sections, descriptions of patient deaths, and coping with patient deaths. 


\section{$\underline{\text { I. Descriptions of Patient Deaths }}$}

Patient deaths ranged from fetal and infant deaths to elderly deaths. It appears that in some cases dealing with the death of an infant or young child may bring about more emotional distress than when dealing with the death of patients of an older age. Showing emotion after the death of an infant or pediatric patient also seems to be more acceptable in a public setting. It was not uncommon for students to experience emotional distress upon the death of patients. Although not every student described their death experiences with words that implied they were truly impacted by the loss, most seemed to have felt some type of emotion. These emotions included sadness, being upset, and in rare cases even guilt and anger.

\section{Adult Deaths}

The descriptions of patient deaths noted by the students in this chapter exemplify the human element of medicine. Although not common, these experiences are important in that they clearly show how human judgment and error may play a role in the final care outcome. In addition, it may be the case that human judgment and error play a role in producing increased distress and anxiety around patient loss. Specifically, Charles and Derrick faced hardships as they dealt with the deaths of patients that were not only unexpected, but in their minds also possibly avoidable.

During Charles' rotation in surgery he experienced the loss of a patient who died from a heart attack that his team believed may have resulted from the surgery he underwent to remove a benign tumor. Since the tumor was benign, in Charles' mind the operation may have been unnecessary. Below, Charles describes the events leading up to the death of his patient and how he felt about the loss: 
[The patient had] a benign tumor, it wasn't malignant, [but] it had the potential to become malignant. And he was older, I think he was like 80 or something and the surgeon decided to go ahead and do the surgery just to sort of prevent [the tumor from becoming] malignant...the surgery itself went well. But then two days later he had a heart attack likely an indirect result of having surgery. I mean it's just a huge stress on the body and he is older, so his compensatory mechanisms aren't [as] strong as someone who's younger. So he had a heart attack and died two days later...[So] you know he came in, he potentially didn't need the surgery at all and would have just finished out his life like normal. I think that's what made this particular patient death somewhat emotionally challenging because as a student I saw him from the very beginning. I saw him at his initial clinic visit and his initial evaluation and I mean five days later I was still on service and he died.

Derrick was another student who experienced a patient death that in his mind may have been avoidable. His experience revolved around being on a team in the intensive care unit that was treating a patient for a clot in her lung. When describing why the patient was being treated, Derrick makes note of her alcoholism, which appeared to not be a factor in the patient's being hospitalized, although it possibly contributed to her death. In the excerpt below, Derrick explains the circumstances surrounding the death of his patient:

So we had this lady in the ICU ... and she was a drinker. And we admitted her in the ICU because she had [another medical problem unrelated to her drinking].... and so she's pretty stable but the thing was she was a drinker... and severe drinkers will go through delirium tremors, so not only will they get really upset and agitated but they're at risk for seizures, their heart rate will accelerate, their blood pressure can get wacky, all kinds of those things. So to prevent her from going into DTs you put them on some kind of medicine... And so the first day we admitted her she really didn't need it, you usually don't hit it until two or three days down the road and I think two or three days later obviously we had forgotten about this...So she's getting really agitated, freaking out, being a real pain to the nurses...So she's just kind of a nightmare of a patient in that sense that you don't know what's going on and then you're like oh wait, she's having withdrawals. So we got that under control and then the next day she codes suddenly and dies and I don't think we knew why. And I think we felt a little bit guilty because she was already trending towards the DT state, so whatever it was that killed her certainly was probably at least 
influenced in some sense by the instability of having to go through alcohol withdrawal. It wasn't very well managed on the part of myself and my team and we don't know why she died.

The wording Derrick uses is telling in that he claims he and his team felt "a little bit guilty" and states that the case "wasn't very well managed." Although he concludes by stating that they did not know why she died, it is apparent that Derrick believed this patient's death may have been avoided had she received better detoxification care in order to prevent her body from undergoing such great stress during her withdrawals.

A third student experienced a patient death that also highlights the human side of medicine. In this students' experience, the patient died as a direct result of human error on the part of a physician who made a mistake while performing a procedure on the patient. Below is the student's description of the events leading to the death of the patient:

[The patient] came into the ER saying he had chest pain and my residents thought he was kind of goofy and they weren't taking him very seriously and they were kind of like you know this guy's exaggerating. And I, being the fresh...med student took everything very seriously. I was right there with him, talking to him about everything... So I was taking him very seriously and I kind of got upset that they were blowing him off and then his blood pressure dropped and it turned out he was having a heart attack...but we end[ed] up getting him stabilized. And I talked to him before I went home and he was complaining about back pain. [I] told my resident, and then I get in the next morning and find out he died overnight. And it was that procedure where they do the cath, they put the catheter in this vein in your thigh and snake it up your heart... and they had poked through the vein when they went in and he had bled into his back. And that's why he was having back pain.

In the cases of the three students above, there is an element of unknown concerning what actually caused the death of Derricks' patient and whether or not Charles' patient would have been able to live out his life like normal had he not had the 
surgery which resulted in a heart attack. For the third student, there was a solid certainty that human error caused the death of the patient.

These cases illustrate the human side of medicine and the role that human judgment and procedural error can play in affecting patient care outcomes. Although there was agreement that the heart attack led to the death of Charles's patient, it remains unknown as to whether or not the stress brought upon by the surgery caused the heart attack. This opened the possibility that the patient may have lived longer had he not gone through the surgery, hence there is uncertainty as to whether or not medical intervention worsened the outcome of the patient. Derrick's case on the other hand is one in which lack of medical intervention may have worsened the outcome for the patient. The description of events leading to the patient's death show that the team made a blatant mistake, as according to Derrick they simply forgot to give the patient the medicine needed in order to avoid the symptoms of alcohol withdrawal.

Unlike the deaths noted above, most patient deaths experienced by students involved patients whose deaths could be directly attributed to disease and illness. While students who experienced deaths that were the results of code situations often did not have an emotional response to the losses, this was not the case for some of the other students. Unlike a code situation (where the student may not have even met the patient before) some students interacted with patients on a more personal level for days or even weeks, leading a few to develop an attachment to their patients. One such student, Dennis, describes the death of one of his patients below:

This woman had a disease called hempagisbulgaris, and it's basically where your skin blisters and slides off... and she had all sorts of medical problems... and I was very emotionally attached to this situation because she was not comfortable... So it was a very long drawn out process and it 
was painful to deal with. The nurses were crying during their shift because the patient, though she was unconscious when they would move her she would cry out...And this lasted for three weeks, it was so drawn out. And this woman was in such pain that it was hard. It was hard... and I didn't see any other patients that day. I spent my entire shift with her there because she had no family there and I did not want this woman to die alone... I didn't want to do it. But I really felt that I needed to stay there until she died. And so that's what I did.

In this case it is clear that Dennis felt an emotional attachment to his patient, as he stated that the circumstances surrounding her death created a "very long drawn out process" that was "painful to deal with." In particular, it also appears that Dennis' desire to make sure the patient did not die alone countered his desire to avoid experiencing her death, as he remained with the patient until she died. Similar to the expected death of Dennis' patient, other students described experiences in which the losses of their patients' were expected. The events leading up to these deaths may have represented a challenge, as sometimes interacting with the families appeared to be more difficult than dealing with the actual patient who may have been intubated or incapacitated. Some of the students who experienced the deaths of adult patients made this clear. For instance, when speaking about the loss of one of his patients, Jack commented:

We could see the writing on the wall that he was going to die and he was very demented so he couldn't understand...we'd just have a superficial conversation with him but we'd take the family out in the hallway and say, he's not going to make it and next week most likely he's going to be gone, it was really tough. I actually found it harder to speak with the family in that situation because the patient was demented, he didn't understand the gravity of the situation but the family, they were accepting but they were extremely emotional about it.

In Jack's case it was clear that the fact that the patient was not coherent and able to understand his condition made it easier for him to deal with having to interact with a 
dying patient. The fact that he had to interact with the patient's family, however, countered this, making it a difficult situation.

Alexandra, who lost an adult patient during her rotation in the ICU also spoke of what is was like to interact with the family prior to the death of her patient. Just as family interaction influenced the way Jack experienced the death of his patient, Alexandra's experience was also clearly affected by this. In her case, experiencing the actual death of the patient was easier to go through rather than the days leading up to his death.

In the ICU our team lost a handful of patients the month I was there but one was my patient that I followed daily and interacted with the family. His death was a situation where clinically he was getting worse and worse, he had an underlying metastatic cancer...[But] when the actual moment came that he passed, I think I was actually ready because I had spent so much time with the family talking about you know, what's really going to happen...so I think I was ready by that time so it wasn't emotionally difficult. The days leading up to that were emotionally difficult because you're with the family who's crying and upset and distraught and you know telling you all their memories.

It is clear that in some cases students do find patient death distressing. While the students above found it difficult to interact with the families, there were also situations where the students didn't have to interact with families but found the loss of their patients to be upsetting nonetheless. Ava, for instance, lost a patient whom she had helped to care for nearly the entire month she spent on her rotation. She spoke of seeing the patient one last time before he died and stated, "He was unconscious...but he had a smile on his face. I stood there for a while by myself. I actually cried...The attending kind of had tears for himself too, and he was like, 'There's nothing we could have done'."

The experience of having a patient who is unknown to the student code appears to be the most common type of death that does not trigger an emotional reaction. In all other circumstances, feeling some type of emotion after the death of a patient was 
common. Nowhere else was an emotional reaction to death as strong as when the patient is an infant or a child.

\section{$\underline{\text { Pediatric Deaths }}$}

For obvious reasons the death of a pediatric patient is different than the death of adult and elderly patients. It is difficult for some individuals to deal with the deaths of children, as they are viewed as being innocent. Most have a tendency to want to protect children from pain and suffering, which are two things they may experience during the dying process. The death descriptions below illustrate the various ways in which medical students experienced and learned of the death of their pediatric patients, which included two infants, a young child and a teenager.

Michelle and Sandral were two students who both struggled with the events leading to the death of their infant patients. Michelle spoke of the immediate events leading up to her patient's death and referred to it as a "terminal sedation" as her team decided to "give him enough morphine to resolve his pain and...to suppress [his] air hunger...so he could...die peacefully." While the death of her patient was expected, it was nonetheless very difficult as she described it as "really, really tough."

The other student who also experienced the loss of an infant was Sandral, who sought permission from the Chief Resident to take a day off because she was so distressed about the current condition and impending death of her patient. She spoke of her patient's condition prior to his death and noted that, "He went from being a potential heart transplant patient to this baby's probably going to die any day now." While describing how she initially found out he had died, Sandral stated, "the blinds were 
closed on the door to his module. So I knew he had died because they don't close the blinds unless there's a death."

Two other students described the loss of pediatric patients of an older age. Dylan experienced the loss of a 7 year old cancer patient. Below is a description of his last interactions with the patient prior to his death:

So this kid was just the cutest kid in the world. He was in bed watching the Little Mermaid...[and] he was joking with me. I made a joke about him being related to Mariel because she had red hair and he did too. He giggled at it. And I told him I was going to see him in a couple of days because I wasn't going to be there that weekend. So I told him I'd see him on Monday and he said okay. Sunday night he got very, very sick...and ended up dying.

Alexandra was another student who experienced the loss of a pediatric patient.

Although she was no longer a member of his treatment team when she learned of his death, his passing clearly affected her.

I had a patient on pediatrics who had a very bad cancer and they were going to try to treat him at [a children's] hospital because they had some research protocols that he would have qualified for. And I actually went and visited him once he'd been transferred off of our unit. And the kid was so cool, I mean, really nice guy...so I saw him that one time when he was on a different unit and then I was in different hospital systems where I didn't have direct access and I didn't think to pull open the records [but then] one day when I was walking past [the hospital] I saw a kid sitting outside that reminded me of that kid. And I'm like, "Oh my gosh, I wonder how he's doing." And when I pulled up his information his death report was in the system and I started crying.

\section{Coping with Patient Deaths as a Medical Student}

The findings suggest that nearly all of the students who experienced a patient death experienced some emotional difficulty. Although every case is unique in terms of the age of the patient and the circumstances surrounding their care, students tend to mention similar ways of handling and dealing with such loses. The students mentioned 
several strategies they used to cope with the deaths of patients. These included talking, carrying on with physician duties, participating in rituals after infant deaths, crying, and turning to religion. Through employing these coping mechanisms, the students interviewed during this research have managed to handle the deaths of patients.

\section{$\underline{\text { Talking }}$}

Although coping mechanisms seem to vary from student to student, there does seem to be a recurrent theme of coping with death by talking about their patient death experiences. Students frequently mentioned talking to other medical students, their own families or sometimes even their superior physicians.

It was not uncommon for students to mention talking to their family members and partners about the deaths of patients as sometimes they were actually physicians or other

medical students themselves. Charles for instance, turned to his brother, a surgeon, when he lost his first patient as he stated "I called him and asked him you know, what was it like when you lost your first patient, how did you deal with it, what did you feel?" Meredith also spoke of talking to her husband who is also a medical student. Lastly, Rachel mentioned talking about patient death with her mother, who is a physician.

It is not necessarily unique that these students have other family members who are also doctors that they can turn to for support, although talking to other medical students seems to be the more predominant coping mechanism. Medical students obviously share similar experiences as they go through their rotations and complete the third and fourth year of medical school. This is illustrated in Madison's explanation as to why she talks with other students and her boyfriend (who is also a medical student) about patient death more so than her own family: 
[I talk with] just my friends in general. I mean we talk about school and situations all the time and I'm dating another med student so if anything happens he's the first person that I call. I'm very close to my parents and I love to talk to them but I just feel like when we talk it's not as fulfilling because I know they can't fully understand and you know I dated a nonmed student for a long time and even then it was hard for me because I'd want to talk to him and I just never felt better because I knew that he just couldn't quite understand what I was going through.

Although most of the students felt comfortable talking to either family members or friends who were also medical students, some did talk with other physicians who are seen as their superiors. Derrick, for instance, stated:

I've had some really great residents who whenever a patient passes away they always take the time to say hey, how do you feel about this?...So I've had some really good talks with residents and usually they initiate that. And that's appreciated.

Kenneth was also another student who spoke with a resident about the death of a patient. Although he did not have a conversation of great depth, he nonetheless expressed his thoughts about life and death to his resident as he spoke of "talking about it with the attending and resident about how poignant that was, that change from just sitting and [being] somewhat labored breathing to not being alive... and [they] agreed that it's amazing how quickly things can change." The importance of talking while experiencing patient death was also emphasized by Josh:

It's okay to talk to people, but select the right people to talk to. You need to be careful who you talk to about patient death and you need to find that person who you're comfortable talking to. A friend, an intern, an attending, and you will find that person. It may not happen your first month, it may not happen your first six months, but you will find someone to talk to and it could even be a family member or something as long as you don't break any rules in terms of privacy. And find that outlet because [experiencing the death of a patient is] not something that physicians should have to deal with alone. 


\section{Carrying On with Physician Care}

While patient loss may take an emotional toll on those who experience it, it is nonetheless part of the profession that the students are training to enter and something that they must deal with as they continue to care for others. It was not uncommon for students to mention carrying on with their student duties as a coping mechanism as it helped the students cope by allowing them to balance the loss of patients with the fact that there are still others out there whom they can help. Luke, for instance, stated:

I hate to say it's a tradeoff because I don't really think it is a tradeoff but I think that knowing that we help all these other people makes this one or two poor outcomes a lot easier to deal with. Easier to say it's okay, it happens, [but] don't lose track of everything else.

Looking to the possibility of helping others in the future seems to be a recurrent theme when it comes to coping with patient death. Samuel, for instance, spoke of learning from the death of patients and using them as a way to improve upon patient care in the future:

Without sounding cold, you just do what you do and then you move on...I think for me the biggest thing I can do for a patient dying is looking at what I can learn from it to try to prevent something like that again.

Carrying on with work and continuing to help others is an essential part of medicine regardless of how many patient deaths physicians and medical students experience. The students were not only aware of this but very accepting of it. Alexandra is one student who accepts this as her comments make it clear that to her death is a part of the profession she is entering and something she will continue to experience. She counters this, however, with the fact that other patients will continue to need her care. Below she describes why she feels it is necessary to carry on after a patient death. 
[After I learned of my patient's death,] I was sitting at the computer crying a little bit and then I had to go see my other patients and take care of my stuff. And I think that is maybe one thing that saves you as a physician, there's always somebody else there who still needs your care. So you have to keep going...I mean everybody deals with things differently but I think it can be appropriate to have your moment of grief and then stand up and say, "Well, I'm a doctor. I'm going to know a lot of people who pass away." People pass away every day. It's sad. [But] there's somebody out there who I can help and maybe improve their life.

The theme of carrying on is also illustrated by the comments made by Dennis, who stated that, "If you're dealing with living patients you have to go on to the next patient and maintain positivity or at least neutrality so that you're doing them justice in terms of their care and treatment."

\section{Participating in Rituals after Infant Deaths}

Two of the students who experienced the death of infants mentioned helping in the rituals that are commonly performed after such deaths. Participating in these rituals helped both of these students to cope with the deaths of their patients. For Sandral, assisting the nurses in the ritualistic act of making moldings of the baby's feet and preparing his body to be seen by his family was the next step in her caring for her patient. In the description below, it is clear that she felt her role in caring for him as a patient did not end in light of his death:

I was standing there watching them do the molding and I [thought] I really should help them. So I just asked if I could help and I helped make the molding of his feet and then they clear off the crib, they take all the monitors and stuff away for when the family gets there and they put him in special clothes. And they have special blankets and they comb his hair, like brush it down [and] make the area look really neat and pretty. So I just helped do that [because] I had taken care of him the whole time. So to not take care of him now didn't make sense. Just continuity of care. Alright, you were my patient when you came in and you're still my patient even after you died.

The other student who participated in a similar ritual during one of her rotations 
was Rachel. Like Sandral, Rachel spoke of staff preparing the deceased baby to be seen by the family. In Rachel's case, she clearly felt that this helped her deal with the loss, as she stated:

They dress it just like they would a normal baby and I think it really helped me. I don't know, just participating in that process of getting the baby dressed and giving the baby to the mom and making sure it had a bow on its head. All those little things we do for a lot of babies. Recognizing, embracing this as a person and embracing this as a death instead of saying "Oh, its just tissue, we don't need to deal with this."

Clearly in the cases of Rachel and Sandral, they coped by participating in the rituals of preparing the baby to be seen by the family. Rachel especially seemed to benefit from the experience as it helped her express that the baby was at one point a human life. Much like the ritual of the funeral in our society in general, the ritual that is performed after the loss of an infant also appears to be an important part of the culture of medicine.

\section{$\underline{\text { Crying }}$}

A handful of students mentioned that they cried after experiencing the death of their patients. While analyzing the interviews it became apparent that in addition to crying being an initial emotional reaction, it is also a coping mechanism that is employed by some students. It has been noted by some that the culture of medicine emphasizes professionalism and stoicism (Ludmerer 1999; Kinghorn 2010; Goldberg 2008). Perhaps for this reason, some of the students interviewed spoke of not allowing intense emotion to show while in front of their superiors. For instance, when I questioned Jack as to whether or not it was appropriate to express worries or concerns over patients and their possible deaths to the physicians above him, he commented: 
I think at least for me and my classmates you don't want to show a lot of emotion in front of your physician because they're essentially grading you and you want to be very professional around them and it's not always appropriate to cry in front of them.

Jack's language here implies that crying is not professional and perhaps in his mind under the experiences he has been through with losing patients, it would not be appropriate. The attitude concerning showing emotions to superiors varied from another medical student who actually grieved with her intern. While interns do not hold the same power over the medical student as the attending physicians do, it is still certainly interesting to note that the intern is in a position of power over the medical student, and in one student's case, her intern let her know that it was okay to show emotion. While discussing the reactions of the medical students and house staff to the death of an eightmonth old pediatric patient, this student commented:

My intern that I was with when I was on call that night when he died ended up coming in [along with] the medical student that was primarily taking care of him. [She came] in because she really bonded with the family and I mean we were just kind of all sitting there crying while our intern kept having to pause, dictating the death note...my intern and I after that were like okay we'll answer pages but we're just going to take a break, get away from the floor. We went down to McDonald's, got chocolate shakes, and she's like you know it's okay to be crying. It's okay for all of you to be crying, it says good things about you. It's not that you're bad doctors because you can't step back (Michelle).

Ava is another student who expressed strong emotion with her superior over the death of a patient. In this particular instance, Ava recalled seeing her patient in a vegetative state shortly before he passed away. The interaction that she describes to have taken place between her and the attending physician is similar to that of Michelle's as it appears a superior physician provided the medical student with support.

I kind of stood there for a while by myself. I actually cried... [And] the attending kind of had tears [in his eyes] too...[And] I really appreciated 
this attending. He kind of sat down with me and he was like, you know you did your best, you did your best and I did my best.

Unlike the two instances above where crying was not deemed inappropriate, it appears that for some of the other students crying is not something they would find appropriate or at least not consider doing in the hospital setting. These students mentioned crying over the loss of their patients but usually waited until they were alone or in a private area to cry. Josh, for instance, spoke of the emotional reaction he had when he found out that his patient had died. While he was at work, he was told the news that his patient had passed away and obviously felt sadness as he explained that he had to leave the room to collect himself for a few moments. It was clear that he either left the room to cry or because he was worried that he was going to cry as he stated:

It would have been out of place to let those emotions show at that time in that particular situation. Maybe not for some people but it was for me. And I don't know if that's because of my gender or because of my upbringing or just my personal values but I don't think I would have felt comfortable in that situation being like this has really affected me. You know I had to take care of it on my own.

Similarly, Dennis also spoke of having emotional reactions to the death of patients when he claimed that he allowed himself to "emotionally experience people's deaths outside of the hospital setting." Just like Josh, Dennis does not wish to openly grieve for his patients in the hospital setting but would rather do so alone, out of the sight of others. Dennis stated, “On my ride home sometimes I can't keep it in and I'll end up crying or end up grieving in some way." Charles is another student who also cried over the loss of his patient, although he also did so on his car ride home when he was alone. Lastly, although she acknowledged that she often cries, Fourth year student, Susan, made 
clear the mentality towards crying in the culture of medicine when she stated, "There's no crying in baseball. There's no crying in medicine. Not in public anyway."

Ultimately, in light of the comments made by the students above, although some staff and faculty physicians may not condemn crying, it is clearly something that the culture of medicine does not condone as students are socialized to become strong and independent, not only when concerning their professional development, but also concerning their emotional development.

\section{Turning to Religion}

Some students also noted using religion as a coping mechanism which appeared to provide these students with comfort through various ways. For example, Mary stated "it's comforting to know that you will see your loved ones again and that they're in a better place." Her religious beliefs clearly affected her being able to cope with the loss of patients as when referring to how she felt about the circumstances of a pediatric patient, she commented:

To see this little boy now who's just laying there with his eyes closed, zero quality of life, it's just a machine breathing for him. So it's either that and dealing with that for the rest of your life or just accepting the reality [that] these are the cards that you're dealt and that this is God's will. You just have to let him go.

Sandral is another student who also spoke of "God's will" concerning the death of

a patient. In her case, religion helped her feel less helpless as she and her team were

unable to prolong the life of an infant when she stated:

We're all doing everything we can and basically it's God's will if this baby dies. And you know we should all still do what we're supposed to do but you know a lot of the neonatologists will say eventually its just out of your hands. So I think I just had to remind myself that a couple [of] times through the rotation that you know, we're doing all we can, but it's ultimately not in our control. 
Religion may therefore alleviate the helplessness medical students may feel when medical treatments are not enough to relieve the suffering or prolong the life of their patients. Sandral and Mary both took comfort in the belief that the ultimate fate of their patients was not in their hands but instead in the hands of God. In the same manner, prayer was also mentioned by Alexandra and Derrick. Although Alexandra only acknowledged believing in a higher power and not necessarily "God," both her and Derrick mentioned praying. Alexandra may have turned to prayer not necessarily out of true belief but rather desperation, as she stated "I prayed a lot. I don't usually pray all the time. [But] I think I prayed like twice a day that whole month because I just felt like, 'Somebody help these people'." Derrick also referred to prayer as something that, “Tends to make you feel like you've done something, or you feel better about it if you at least give thought...to something like death."

Religion was therefore something that these students embraced during their rotations as they experienced the loss of patients. Although religious beliefs may often clash with the concept of medicine and science, these students appeared to be able to reconcile the two. The overriding theme of religion in the case of Mary and Sandral seems to be that it relieves them of a burden as they feel better and less helpless in believing that their patient's fate is ultimately out of their hands. This differs somewhat from Alexandra and Derrick who seem to find comfort in performing the actual ritual of praying, especially Alexandra who may not even really believe in God.

\section{Conclusion}

The students in this study had various death experiences which they appeared to be able to cope with by employing the mechanisms explored above. Whether or not the 
students will employ different coping mechanisms as they advance in their training and become medical doctors remains open to question. This is one area where research could be expanded in terms of exploring how individuals cope with death when they are students as compared to when they are medical doctors. Such exploration goes beyond the scope of this study, however, as my sample consisted solely of medical students. As talking and carrying on were the most frequently mentioned coping mechanisms, more emotional and personal ways of dealing with death, such as crying and turning to religion were nonetheless present amongst the students I interviewed. Carrying on with physician duties is perhaps the most understandable coping mechanism, as the students find themselves in a highly structured learning environment in which heavy patient loads and long hours require that they be able to focus on the task at hand. Lastly, it is worth noting that both of the students who participated in the rituals after the death of their infant patients appeared to feel some level of comfort in doing so. Whether or not participating in other rituals after the death of adult patients would help students to cope with loss remains unknown, as none of the students reported attending the funerals of patients. 


\section{CHAPTER SIX - ATTITUDES TOWARDS PATIENT DEATH \\ Introduction}

This study also examined how the medical students viewed various aspects of death related issues. Specifically, I attempted to explore three issues which include how students view patient death in general, what they think constitutes a good death, and how they feel about physician assisted suicide.

Several common themes emerged in each of these areas. For instance, most students did not perceive death to be a failure, and those few who did had specific experiences in which the human element of medicine played a role in the death of their

patients. In regards to what students think constitutes a good death, there were several common themes including being pain free, patient autonomy, and the family's acceptance and understanding of the death. The last issue explored in this chapter is that of physician assisted suicide, something which most students were uncertain about or opposed. This chapter is broken down into three main sections being (I) general views of patient death, (II) the meaning of a good death and (III) attitudes towards physician assisted suicide.

\section{General Views on Patient Death}

General discomfort with death seems understandable, in that some students may just not be comfortable around death and therefore choose fields that avoid the dying. For example, Rachel explained:

There's definite fields that are going to deal with [death] more and certain people aren't going to go into [them] because they're not comfortable with it. Like geriatrics, if you're not okay with people dying and talking about it you shouldn't go into geriatrics because a lot of [patients] are going to die. And some people will make their career decisions based on that. They'll just say, I'm not comfortable with that, I don't want to do that, I 
want to work with a healthy population that's not going to die (Rachel).

What is of interest here though is whether the students held general views of death as a failure, an idea that has long been documented in the literature concerning the medical professions' view of death and dying (Hooyman and Kiyak 2008; Dickinson and Leming 2007; Dickinson, Still and Tournier 1999; Rappaport and Witzke 1993). In contrast to such literature, however, many students maintained the attitude that death is not a failure. The majority of students made it clear that in general they do not view death as a failure and that they do not perceive the academic setting in which they study to promote such a view. In the few instances where students used wording that implied the death of their patients was a failure on some level, the deaths mostly involved circumstances in which human error or human decisions affected care outcomes. These later instances are discussed below, followed by the more common experience of not viewing death as a failure.

\section{Perceptions of Death as Failure in Specific Cases}

Whether students view death as failure may be influenced by what kind of effect the decisions made by the medical team has on patient outcome. The experience Charles had with patient loss exemplifies this, as he appeared to view death somewhat as a failure in his mind as the patient underwent surgery that was not necessarily needed and suffered a heart attack. His medical team thought the surgery may have increased stress on his body because of the surgery and Charles commented:

I think that one was a hard one to look at both as either a failure or a part of life. So I think the majority of our team saw his death as a failure. I think a few of us looked at it as well, maybe his surgery caused the heart 
attack but the heart attack is what caused his death. I don't know if it was a rationalization... it's pretty hard to think about that way.

Even with making such a statement, however, Charles was still clear on his belief that death is something that is "part of life" and "a part of medicine." In light of the circumstances surrounding his experience, it makes sense that he may have viewed the loss of this particular patient as a failure while still being able to maintain the belief that death is not always necessarily something that should be viewed as such. Derrick also held the same view point, as he never spoke of viewing death as a failure, but at one point during our discussion, while trying to recall patient deaths, stated:

There's a couple I feel bad about. This is the thing about medicine is even when bad things happen there's like ten different steps that ended up causing that bad outcome and you're never sure which one you caused. I'm trying to think which one was the biggest mistake.

While Derrick never made any other statements that framed death as being a failure, it appears that he acknowledges the human element of medicine which can influence care outcomes. One student also spoke of the loss of her first patient with words that implied failure, although she acknowledged that she eventually reconciled this with the idea that medicine is subject to human error. In referring to the loss of her first patient, who died as a result of a mistake made by one of the physicians on call, the student commented:

I was really upset about that and I really blamed that guy for a long time and I know who he is but he has no idea that I think this. But the more I think about it and the further I get in my training I realize you just can't catch everything. You're only human and these things happen.

In this particular student's experience, it appears as though she stepped back from viewing death as a failure and reframed the experience as to remove blame from the physician. Perhaps it could be argued that in this student's case she does not view death 
as a failure because it is a failure. In other words, if human error is what caused the death of a patient, this places a large responsibility on physicians to never make mistakes and possibly a large amount of guilt on the physician's part if such mistakes are made. In stating that, “you just can't catch everything. You're only human and these things happen", this student appears to be displacing responsibility away from the physician who made the mistake as she emphasized (perhaps unintentionally) the human element of medicine.

It appears that these particular students understand the human side of medicine in terms of how error and decision making can affect care outcomes. This may allow them to perceive some deaths as failure, but refrain from viewing death in general as failure. Lilly was the only student who made comments that framed death in terms of failure. Take for instance her emphasis on the fact that because she is a student, she feels safe when it comes to patient death since students are not held responsible for care outcomes like interns and residents are.

Since I'm at the bottom of the totem pole I feel pretty safe. Because usually when dealing with death it's like lawsuits, it's like who's to blame, what did you do wrong. So when that comes to place its really not me, first it's like the staff, what did you do wrong and then if you didn't do anything wrong, what did the resident do wrong and then at the very last it would be what did the medical students do wrong. But that doesn't happen, that doesn't ever happen because I think we're protected as medical students. Right now for me I do my best to prevent it but when it happens I know it's not my fault that I didn't pick up on something.

It is possible that Lilly's framing of death in terms of lawsuits and something that results when physicians do something "wrong" may stem from the one direct death experience she had as a student in which a deceased patient's spouse threatened to file a 
malpractice suit against an attending physician and a hospital. The majority of the other students, however, did not perceive the deaths of their patients to be failures.

\section{Death is Not a Failure in General}

Most students seemed to be somewhat comfortable with the possibility of losing patients. Janet, who is planning on specializing in oncology commented, "[It is] their job to deal with death. You have to be good at accepting it at some point." Also, Luke made it a point to acknowledge that death is seen as part of the "business" which he is entering. Even in cases in which there is no obvious medical reason for the death of a patient, Luke still accepts death and does not view it as any type of failure. This is apparent in the following comment he made during the interview:

I think [the medical students I know of] accept [death] as part of the business. We try our best and we help people as much as we can, but sometimes things just turn south for no apparent reason. No foreseeable reason on our part. You can get two patients with the same disease and one could get better and one could get worse. And for the most part, people accept that as something that happens and there's nothing we can do to really change it...I think overall it's just viewed as part of the deal. It's something that happens. It's part of the business and the business we're in is helping people and trying to save lives but part of that, you're going to have people that die no matter what you do and that's okay, I think there's nothing wrong with that.

Luke's willingness to accept patient death is obvious in the above statement.

There are many instances in which death may be framed as a failure in medicine, whether it be a failure on the part of medicine to cure serious illness or a failure on the part of medical doctors to improve the health status of their patients. Luke clearly rejects such ideas, however, in viewing death as something that is "okay." It is important to note that although Luke accepts death, he does not credit the schools or its curriculum for his attitude towards death. Therefore, Luke views death as a part of the deal of the business 
of medicine but it is partially unclear as to why. Other students, however, specifically

credited the medical school's culture and curriculum as to why they view death as something that is not a failure but instead a natural process.

In response to questions concerning how the formal and informal school curriculum influences their thoughts and attitudes towards patient death students made comments that clearly reflected that they believed the university's faculty and culture did not promote the attitude that death is a failure of any kind. Instead, most of them described it as a natural process, and emphasized that it is something perpetuated by this particular medical school. For instance, Josh stated that:

[In] my particular class, the people who taught me made it very clear that death is a natural process. It is not something to be avoided, it is not something to fight at all costs. It is something that we need to accept as physicians as the natural completion of a life, not the failure of the medical profession to extend somebody's life.

While Josh's view may change as he continues through medical school and eventually becomes a professional in the medical sciences, it is apparent that at least for now, as a student, he perceives the medical curriculum of his school to teach that death should not be viewed a failure on the part of the medical profession. This is something that other students also emphasized. Take for instance the comments of Janet, who was responding to my explanation of the findings of an article regarding medical students' views of patient death. She stated, "I don't feel like the culture here [teaches us] that death is a failure. I don't feel that at all. I never have.” Jack also commented on the school's focus on death being a natural process when he talked about the potential death of patients:

As much medical knowledge as we have, the patient is [sometimes] going to die and I don't know if its [here] in particular, but a lot of physicians 
say that death and dying is a natural experience. Especially [at this school], they focus more on that death is a natural process. It is something that is going to happen and you have to be ready for it.

The statements made by the medical students throughout the interviews seem to maintain, for the most part, that the medical culture at this particular university does not propagate the idea that death should be viewed as a failure. Instead it seems to do the opposite as these particular students perceive the curriculum and faculty to be willing to accept death not as a defeat but as a natural process.

A couple of students gave plausible reasons as to why they feel the curriculum has not led them to view death as a failure. Josh was one student who stated:

I think it's a generational thing...And I think a lot of physicians have trouble with [accepting death] who were raised in or taught in an earlier era where it seems like medicine is so promising that one scientist at one point wrote that infection would be a thing of the past after we developed all these great antibiotics... So we have this time period where we thought medicine could cure all and people would be living 180, 200 years. It's just not going to happen. And I think that it's difficult to change that after you've been practicing that way.

Josh has what may be considered a more realistic view of the potential of medicine to save and extend lives. His comments illustrate the idea that some students may accept the fact that medicine is sometimes limited in the potential it has to do this.

A generational gap was also mentioned by Rachel when she spoke of working with physicians who appeared to care more about the patient's quality of life during their final days as opposed to quantity. Rachel makes it clear that she believes such an attitude would not have been held by physicians several years ago as she states:

In all my situations the doctors have not been the one pressing for more aggressive care. I've never seen a doctor saying we need to do more, we need to do more. It's always been the family who wants to do more and the doctors are just realizing more and more like this is not going to work it's too much...But I think it's very accepted now to say enough is enough 
whereas I don't think that was the case even just ten or fifteen, twenty years ago.

Another student who mentioned the change in attitudes concerning death amongst the medical profession was Dylan, who commented:

Although the majority of our profession is based on fighting death, I don't see death as an enemy... The culture is changing with our generation of physicians. If you were to do the same questionnaire with physicians that have been working for twenty years or longer, it would be totally different. So it's definitely changing for the better with our generation I would say.

It is interesting to note that Dylan believes his generation does not view death as an enemy, or a failure, and that this is something that represents a change for the "better." It is also worth noting the similarities between Josh's and Dylan's belief that the culture of medicine has become more accepting of death in light of a more realistic view of the potential of medicine.

Kenneth is another student who also placed emphasis on the idea that death is not a failure when he commented, "I've gotten the impression working with people that all the physicians are very honest with themselves and not so egotistical to think that they can prevent death at every corner." Again, such wording reflects the belief that even though death is not something that medicine can always prevent, it should not be viewed as a failure of medicine to extend lives or of the physicians who practice medicine to extend lives. Some students also mentioned the difference of quality versus quantity when it comes to the end of life circumstances of patients. Their comments and opinions on this topic can be seen as questioning the idea that death is actually a failure, as they stress the importance of the patient's quality of life during their end of life care rather than how much longer the patient's life can be prolonged. Madison, for instance, stated: 
Even if it will extend a patient's life by a week then we have to try it even if it costs ten thousand dollars for this medicine. And I don't really know when that happened or how we kind of became like that but I think sometimes we need to step back and think about the patient's quality of life instead of length of time.

Lastly, two students did mention a reason as to why they do not view death as a failure. Although they do play a supportive and pro-active role in caring for patients, medical students are obviously not ultimately responsible for the care of their patients as they are overseen by multiple layers of superior physicians. The students work under the supervision of an intern, a resident and then an attending. Mary and Susan both credit this as a possible reason as to why they do not view death as a failure. Mary commented:

Maybe that's why physicians feel more like failures than the students do because...the physician is trying to fix [the patient] and I don't think we're really at that part in our training yet where we're trying to fix people. We're getting there but that's the job of the physician to do, so I think it really has to do with we're not ordering all the tests that are negative and ordering all the treatments that are failing. Maybe that has something to do with it, I don't know.

In the same manner, Susan commented that she believed that if interns had been selected to be interviewed for this research different results would come about. She stated:

At the end of everything there's somebody else that's going to sign off on the case that's in charge of you. And if you interviewed interns I think you'd get a different point of view because that's the first time where it's on you....Probably a lot of people think of it as a failure once you're actually the one responsible.

Such comments bring to light the possibility that these student views of patient death may change once they become interns. 


\section{The Meaning of a Good Death}

The students mentioned many similarities concerning what constitutes a good death. Students commonly placed emphasis on the idea that a good death is one in which quality of life, not quantity is considered and the patient is free of pain, and one in which patient autonomy is respected (by both physicians and family members), and one in which the family understands and accepts the patients' death. As demonstrated in the previous chapter, the latter appears to be an important part, as interacting with family's of the dying seemed to be something that was difficult for some students, even more so than interacting with the dying patient (who may have already accepted their prognosis or is otherwise incapacitated). The majority of students were able to give at least brief descriptions of what constitutes a good death, as only one student claimed that, "There's never a good death." When I questioned the remaining students as to what in their mind constitutes a good death, similar themes arose.

\section{Quality of Life versus Quantity of Life}

The students frequently placed an emphasis on quality of life rather than quantity and often noted that a good death is pain free and one in which the patient is comfortable.

The issue of quality of life is obvious in the following statement made by Alexandra:

A good death is a death that comes in a person who has a very low likelihood of enjoying their life...It's so hard to say these things without sounding like an evil person, because there's always exceptions but there are kids, institutionalized children in this country that we never see on the streets that probably would have been a good death if they had just passed away when they were born because death does not always have to be a bad thing.

It is worth noting her comment that "death does not always have to be a bad thing," which would appear to directly contradict much of the previous research 
concerning death anxiety in the medical profession because it implies that she is willing to accept death.

\section{$\underline{\text { Patient Autonomy }}$}

Although not explicitly stated by some of the students, their wording does imply that they think a good death must involve some level of patient autonomy. Patient autonomy could be the patient's decisions to place a do not resuscitate order or end treatment. It could also refer to their ability to make final decisions concerning where they will die. Although the students never directly state the words "patient autonomy", the following descriptions of what constitutes a good death revolve around this theme.

When discussing what creates a good death, Janet, commented, "I don't know, just truly letting the patient die how they prefer to die would be a good death I think." Other students went into greater detail concerning what factors help create good deaths. Rachel emphasized "control" as being an important factor in creating a good death. In the following statement, she links control to having a sense of dignity during the end of one's life.

I think dignity is huge. I think having a sense of dignity at the end of your life. I think control for a lot of people is part of that. Having control over the things that happen to you as much as possible. Whether it's just controlling where you are when you die or controlling how you die sometimes. So dignity and control.

Although she never states the phrase patient autonomy, Rachel's words imply that the patient must be able to control where he or she is when they die and how they die in order for them to experience a good death. Patient autonomy is therefore emphasized in her statement although she never explicitly uses the phrase itself. Similar to Rachel, Jack also used the word "dignity" to describe what helps create a good death. Dignity in his 
terms means that people have a certain amount of control over how they experience the

end of life. Although Jack also mentions dying in the presence of loved ones as

necessary for a good death, he places a greater emphasis on patient autonomy when he

makes the following statement as to what in his mind constitutes a good death:

Dying with dignity again, having people they love around them. Not doing things for them that they didn't want, like if they didn't want a resuscitation, like a DNR, do not resuscitate, that we don't do anything outside of their will. That if they were to pass away we don't do chest compressions to try to revive them again. That they're not dependent on like a ventilator or a breathing machine if they didn't want that. That kind of they just go how they want to go with the people they want to be with at the end of their life. I think that's important. I think there's a lot to be said about dying with your loved ones around you and kind of in an environment that's respectful to your wishes sort of thing.

Other students also emphasized that allowing the patient to die how they so

choose helps to create a good death. Kenneth for example, explained that a good death is one where "the patient has their wishes known." Michelle also stated:

I think that if it's what the patient wants. Like I know exactly what I would want if I were in that position as a patient, and so I really feel like if things are not according to a patient's wishes that's not a good end. If a patient wants to die in the hospital pressing till the very last moment, that's what they need to have.

Patient autonomy is clearly important to these students. This may represent a broader shift from physician beneficence and medical paternalism to patient autonomy in medicine in general, which is something that has previously been noted by researchers (Chin 2002; Pellegrino and Thomasma 1987).

\section{$\underline{\text { Family Relationship Concerns }}$}

In addition to patient autonomy being a primary component of creating a good death, some students also spoke of concerns pertaining to the patient's family. Janet, who stressed patient autonomy also stressed that, "Having a family informed about 
what's going on is huge...I think the worst thing is having a family be really upset with a death because they didn't know [what was happening]."

Ava was another student who stressed the importance of relationships needed in order to create a good death. She mentioned that family members should be involved and stated, "I think the family is a very important issue." In addition to family members, she also stressed the importance of the presence of the physician and even the medical student at the time of the patient's death. The following comment she made concerning what a good death entails makes it very clear that in her mind, the relationship between the physician and the patient is a crucial part of helping the patient die peacefully:

It would be very nice if the actual physician who was taking care of the patient can actually be there...I think a death is a good death when the person had a lot of time to prepare their final moments by having a long conversation with their physician...Actually not just medical talk but real life talk and actually the physician not just being a doctor but a human being having that talk with the patient.

A couple of students also made note of the relationship between the physician and the family during the dying process and after the death has occurred. Experiencing the loss of a patient can be more difficult when family members are openly upset and struggling to deal with the passing of their loved one. Nowhere is this more apparent than in the comments made by Charles, who started to describe a good death in terms of whether or not the medical team in charge of the patient had done everything possible to prevent the death, but then went on to describe the important role that the family's acceptance of the death plays in helping to create a good death:

I think a good death is one where the physician can safely and competently say we did everything we could. I think first and foremost that's most important...But more importantly I think is how the family deals with their family member's death. Coming to terms with it, understanding it. Not necessarily accepting it but maybe understanding 
it...And also I guess kind of how the patient himself or herself accepts death. So I think it's a pretty large combination of [a] small medical aspect but I think a big part is just how the family deals with it and how they feel about it. I mean the patient's care doesn't end with the patient's dying, the patient's care, to me, ends with the physician supporting the family through that process.

The family's understanding and willingness to accept their loved one's death was also emphasized by Luke, but in rather different terms. Instead of being concerned with the well being of the family after a patient's death, Luke perceived a good death to be one in which the family has accepted the patient's wishes concerning how they want to experience the end of their life. Needless to say, patient autonomy is inherent in his description.

[A good death is] I think like I said before having everybody on the same page. And if the patient has made their end of life decisions, they have a living will. Usually they've tried to convince their family that it is going to be okay, because it's inevitable that that is what we're going to follow. And so if they have already done that, then I think that would make it a lot easier because usually the family's on board and everybody's together and its sad but it's okay because the family's okay with it, although they may be sad like anybody would. I think that's probably what makes a death a good death. Is when everybody's on board, the patient has made the decision and they're okay with it and then the family's also okay with it.

Kenneth was another student who, like Luke, also emphasized the family's acceptance of the patient's wishes. From the description he provides, it appears that again, the family's reaction to the dying process and how they cope with the actual death affects whether or not the death is in fact a "good death." He explained this when stating:

[A good death is] one where the patient has their wishes known. I think that makes it so much easier on the families and the physicians for that matter if they have clear communication with the family members however it may be, living will or do not resuscitate orders, those types of things that make it easier for the families to let go of the supportive measures that we have available. 
Although the medical students above seemed to emphasize family relationships because they care about the emotional well being of their patients and their patients' families, some may be concerned with the family's acceptance of a patient's death for additional reasons. Lilly, for instance, made it clear that when a patient's family is more accepting of their death it can help to create a good death because it lessens the potential for a lawsuit:

You know after I train if I have a death the first thing that would worry me would be would I be involved in a legal situation. I think that's kind of a big deal for me because I would be worried about the legal liabilities. So definitely if the patient's family member is accepting of the situation then I would definitely feel a lot more comfortable.

\section{Attitudes Towards Physician Assisted Suicide}

All of the students were asked to share their attitudes towards physician assisted suicide. Although the question did not explain the meaning of physician assisted suicide, the students' responses provided some insight into their own understanding of what they consider to constitute the practice of physician assisted suicide. Physician assisted suicide is: "where you are physically injecting something to kill a patient...you are the vehicle for their death" (Madison); "play[ing] an active role in death" (Sandral); and "[when] a physician help[s] a patient kill himself" (Jack). In other words, physician assisted suicide for these students refers to the voluntary termination of one's own life, such as by administration of a lethal substance, with the direct assistance of a physician. In describing physician assisted suicide, they often contrasted it with the more common and much more widely accepted practice of providing morphine to relieve pain in terminal patients even if it may hasten death. 
At this point it is important to make the distinction between common end of life care terms as they apply to what the students conceive to be physician assisted suicide. In an online ethics in medicine series, Braddock and Tonelli at the University of Washington School of Medicine (UW) define physician assisted suicide as a practice in which, "the physician provides a patient with a lethal dose of medication, upon the patient's request, which the patient intends to use to end his or her own life" (1998:1). Euthanasia, which is commonly mistaken as PAS usually means that the physician would "act directly, for instance by giving a lethal injection, to end the patient's life" (1). Euthanasia appears to be what most of the students I interviewed conceive of physician assisted suicide to be. (There are different sources that define physician assisted suicide differently, however). Terminal sedation refers to "the practice of sedating a terminally ill competent patient to the point of unconsciousness, then allowing the patient to die of her disease, starvation or dehydration" (1). Lastly, providing pain medication that may hasten death is another practice that the UW distinguishes from physician assisted suicide because the intent is to relieve suffering, not to end the patient's life. It is the latter category that most of the students seemed to be comfortable with.

As shown in the literature review section, medical students may experience ethical dilemmas both first hand and through observation during end of life care in hospital settings. Several medical students in this study voiced uncertain or opposing opinions of physician assisted suicide on moral grounds that it was ethically wrong or went against the duty to do no harm in the Hippocratic oath. Regardless of their opinions, all of the students were concerned with relieving pain and suffering during end of life care. All of the students who mentioned the use of morphine during end of life 
care were also okay with the idea of administering high enough levels of the drug to relieve pain even if it could hasten a death. In the cases of the handful of students who discussed their opinions towards morphine use during end of life care, it appears that the means justify the ends, as relieving pain played a major role in their justification for supporting using morphine in dosages high enough to negatively affect a patient's respiratory system.

\section{Unsupportive of Physician Assisted Suicide}

Some students directly stated that they do not support physician assisted suicide. In their responses to questions concerning physician assisted suicide, they were very adamant about opposing it. One student, Madison, referred to physician assisted suicide as being a "vehicle for their [the patient's] death," which, as illustrated in the excerpt below, she clearly opposes:

Well, physician assisted suicide itself where you are physically injecting something to kill a patient, whether they would have died in six months, you are the vehicle for their death at that point, you are causing their death and I am completely against that. I think that you know, you take your initial oath and its do no harm you should always have the patient's best interest in your mind.

Interestingly, one student made a distinction between physician assisted dying and physician assisted suicide. It appears that in this student's view, helping a patient who suffers from a terminal illness to die more peacefully is acceptable but he fears that physicians may end the lives of patients who are not suffering from a terminal illness, which he refers to as physician assisted suicide.

I don't agree with it. I think that for one physician to have that power is too much responsibility for one individual and I think that single physician assisted suicide is not right in any sense. I think that it should be okay for there to be perhaps a separate entity of physicians, not just you know one doctor who says you're dying we need to take care of you and give you 
lots of morphine until you stop breathing. We need to have that person have a check on that power because it can go wrong in so many ways.

You can have people who are doing this to patients who don't really have a terminal condition for instance and then it becomes instead of physician assisted dying, it becomes really physician assisted suicide. (Josh).

Dylan commented, "I don't think there is any room for physician assisted suicide... we have to take the Hippocratic Oath which says first do no harm. And my own personal opinion is that assisting somebody [in] dying is doing harm to the patient." Dylan perceives physician assisted suicide to be contrary to the role of the physician who has taken an oath to do no harm to the patient. Although the role of the physician is often referred to one in which the physician assumes a responsibility to prolong life but in addition also relieve pain and suffering, it is clear that Dylan does not see the need to relieve pain and suffering as outweighing the belief that he should "do no harm."

While the students above made statements that clearly reflected a desire to refrain from condoning physician assisted suicide, many made comments in which they appeared to be trying to reconcile the desire to relieve pain and suffering towards the end of one's life without directly and intentionally ending one's life.

\section{Uncertainty Concerning Physician Assisted Suicide}

While some of the students obviously opposed physician assisted suicide others gave either conflicting or uncertain opinions concerning the matter. Rapport may have clearly played an issue in this, as I was a stranger to the students yet asking them very personal questions concerning their ethical beliefs. It is also worth considering that as medical students, these individuals may not have had enough experience in the area of end of life care in order to make a true judgment as to whether or not they support or oppose physician assisted suicide. Ultimately, however, there seemed to be consensus 
that the means justify the ends in terms of students being okay with the idea of giving dosages of morphine that are high enough to suppress a patient's respiratory system, as long as it is done not to end the life of the patient but to relieve their pain. This sometimes resulted in students making conflicting statements regarding how they feel about physician assisted suicide and morphine use during end of life care.

Nowhere was this conflict more clear than in a statement made by Jack. In the following excerpt Jack maintains an unsupportive view of physician assisted suicide but then describes the use of morphine during end of life care, even if it is used in dosages high enough to suppress a patient's respiratory drive, as "humane" and "accepted." $\mathrm{He}$ makes it clear that he is okay with giving a patient dosages of morphine that are high enough to suppress the patient's [breathing], which may hasten the patient's death. Although some may see the intent of relieving pain and the consequence of hastening a death to exist in both physician assisted suicide and morphine use during the end stages of one's life, Jack is able to separate the two as the following excerpt illustrates:

[Physician assisted suicide is] a very touchy subject. I don't think it's ever right for a physician to help a patient kill himself, but I think there are humane ways of going about it. At the end of life, you know if you give a patient morphine like the pain killer, not only does that treat their pain it actually decreases their breathing capacity. That's a humane and accepted way for you to help them, not really help them die but like help them at the end of life, it's a known side effect, a known adverse effect that high doses of morphine will speed up the patient's death because it will knock down their ability to breath for themselves. So, again that's not in the category of physician assisted suicide, it's a totally accepted method of doing it. I see no problems with that. It's very humane and again I think that's dying with dignity. The patient's, they don't want to be in pain at the end of their life, if you can keep them from being in pain and keep them stable to focus on their family or whatever, I think that's pretty respectful even though you are speeding their death along. I have no problem with that, I think that's humane but like giving someone an injection to kill them, I don't agree with that. 
Another student also made comments along the same lines as Jack, as she is able to separate morphine use during end of life care that may hasten a death and physician assisted suicide. It is obvious, however, in the following comments made by this student that she is hesitant to embrace physician assisted suicide.

Gosh. It's hard for me to say how I feel about that [physician assisted suicide]. It would probably be on a case per case basis, I feel comfortable with the idea of giving someone in pain or someone suffering morphine even if it could lead to their death because it shuts down their respiratory system. So I'm comfortable with that idea that if you're treating pain and the amount you have to give may lead to the person's, or quicken their death. I don't know about physician assisted suicide to tell you the truth. I don't think that I would ever be a part of it (Meredith).

Several of the students responded to the question of how they felt about physician assisted suicide in ambiguous terms. Their responses appear to represent general uncertainty about how pain and suffering should be handled during end of life care, perhaps illustrating a genuine feeling of conflict about being a care provider who is supposed to pro-long life and do no harm while simultaneously relieve pain and suffering. Interestingly, it was not uncommon for students to appear to be sympathetic to the attempt to reduce suffering through physician assisted suicide while still claim to disagree with physician assisted suicide. Take for instance the following comment made by Janet:

I honestly don't know much about it. I'm sure there are instances where it would make perfect sense in a way you know, the patient's just in so much pain, you know helping them out seems more humane than letting them lay there writhing in pain. You know I haven't witnessed it and I really don't know much about it. I personally would not feel comfortable administering a drug that would end somebody's life prematurely because of that drug.

The conflict between the beliefs that physicians should do no harm yet still relieve pain and suffering can be seen in the following statement, as a student attempts to explain 
why she believes some physicians would participate in the act while also remaining unsupportive of physician assisted suicide:

I can see why it's an issue. I can see why a lot of physicians in many situations would feel like this is the most compassionate, caring, loving thing that they could do for this patient. Just because the people that this really applies to are in so much pain. I couldn't do it for moral reasons I'm a Christian and I feel that I have a moral code that tells me killing is wrong no matter what. So I couldn't do it and I wouldn't condone anyone really that did but I can understand why they would feel this desire to help the patient in that way (Rachel).

One student also made a comment that showed obvious uncertainty concerning how he would approach physician assisted suicide. While he obviously does not condemn physician assisted suicide, the comment he made below sheds light on the fact that he is rather uncertain as to what he would do if he himself were ever asked by a patient to help end his or her life prematurely.

As a doctor, making that decision. You know, if the patient asked me, hey, I want to go now, like I don't want to deal with this pain. I'd be like, I don't know what to do. Hopefully I'll never have to deal with that. But it's hard for me to either way...I can see both sides.

Uncertainty concerning their views about physician assisted suicide was not uncommon. When questioned as to how she felt about physician assisted suicide, Alexandra stated, “I don't know. It's a difficult question for me to answer because, I guess I worry about where do you draw the line?"

While the views of the students explored above show the uncertainty felt by many regarding physician assisted suicide and end of life care, a few students were supportive of physician assisted suicide. 


\section{Supportive Views of Physician Assisted Suicide}

While it was not uncommon for students to speak against physician assisted suicide but be okay with morphine use during end of life care even if it hastens the patient's death, two students, however, spoke of physician assisted suicide in supportive terms and were comfortable with the idea of physicians helping patients to end their lives. Pertaining to this issue, Dennis stated:

I think that the laws in Oregon with physician assisted suicide are okay. Though it's not widely used, I think that if a patient has a terminal disease and they want to say when, then they should be able to say when. And to that end I would say if the patient is going to say when let's at least make it something that's comfortable and give them access to it rather than something more drastic like a suicide attempt (Dennis).

While Dennis' statement is more broad concerning how the medical profession should handle physician assisted suicide in general, one student actually spoke of how he himself may handle the issue of physician assisted suicide in the future. Initially when discussing physician assisted suicide the student stated, "I'm fine with the idea and I wouldn't hate practicing in a system that does that although I can't say that that would be a practice that I would engage in." Here it does seem as though he is distancing himself from the practice of physician assisted suicide, but then after taking a moment to gather his thoughts he stated:

I think if I had a patient in my own practice who I'd cared for for several years and it was clear that she was nearing the end of her life and she wanted to end it...if there is a system where it's going to happen I'd rather be the person that takes them through that than having them have to meet some new stranger.

\section{Conclusion}

As they enter the medical profession, medical students may experience a vast range of patient deaths. The individual circumstances surrounding patient deaths may 
influence how they view a particular death, but it appears that those in this study typically do not view patient death in general as a failure. Instead, most of the students view it as a natural process, or at least something that cannot always be prevented by medicine, and they appear to be okay with that. Also, the description that students gave of good deaths and how they feel about physician assisted suicide brings ethical concerns to light (good deaths are pain free, but giving enough morphine to relieve pain may hasten death, etc.) which may change over time. 


\section{CHAPTER SEVEN - CONCLUSION AND SUMMARY}

As individuals complete training to become medical doctors they experience various stages of socialization in medical school surrounding experiences with patient death and the death anxiety that can result from such experiences. For most this begins with interacting with cadavers in gross anatomy class, something that all medical students must enroll in. The socialization process does not end after this class, however, but merely continues as students begin to interact with patients and physicians frequently in their third and fourth years. The findings in this thesis provide an increased understanding of this socialization process as it provides insight into how students experienced gross anatomy lab, how they experienced and coped with the deaths of patients and their general attitudes towards patient deaths. Below, I summarize some of the major findings and suggest avenues for future research.

\section{Chapter Four Conclusion}

Similar to much of the previous research concerning medical students' experiences during gross anatomy lab (Hafferty 1991; Dinsmore et al. 2001; Finkelstien and Mathers 1990), the findings of this study suggest that it is not uncommon for students to experience anxiety or have a strong emotional reaction to working with a cadaver. There are a few areas where the findings of this research are limited concerning gross anatomy exploration and could be expanded upon. The most obvious limitation is that of memory recall. Since I interviewed $3^{\text {rd }}$ and $4^{\text {th }}$ year students there is a chance that important details about their lab experiences were missed, as their memory may have been inaccurate. Perhaps if the students had been interviewed while they were actually enrolled in anatomy they would have given different answers. This may explain the 
difference in findings between this study and previous qualitative research concerning students' experiences of gross anatomy lab, such as Hafferty (1991), who found that some students suffered from nightmares while participating in anatomy lab. No one in this study made note of having nightmares during anatomy.

Another limitation of this study is that not all of the students interviewed attended the same centers. It is therefore possible that the socialization that occurs during gross anatomy lab was different for students depending upon what center they attended. Future studies that are examining the culture of one school would probably benefit from focusing on students who have all attended the same center (if the school has more than one). Future research could also expand upon the affect that taking anatomy courses as an undergraduate may have on students' experiences during their first year anatomy course in medical school as only a few of the students in this study had participated in undergraduate anatomy labs.

\section{Chapter Five Conclusion}

As the students in this study experienced a vast range of patient deaths including infant, pediatric and adult deaths, they frequently engaged in similar coping strategies. The more common coping mechanisms included talking and carrying on with their work. These two coping mechanisms were also common among the students in the research of Ratanawongsa et al.'s (2005) and Rhodes-Kropf's (2005). Some coping mechanisms such as talking and carrying on with work can obviously take place within the hospital setting. On the other hand, more personal forms of coping, such as crying seem to take place outside of the hospital setting, especially when this mechanism is employed by male students. It also appears that the age of the patients affected how students coped 
with their deaths, as Michelle and Sandral, who both lost infant patients found it difficult. Michelle described openly crying with an intern and other medical students and Sandral requested the day off. The latter is something that no other medical students did. Lastly, an interesting area that future research could expand upon is the affect that participating in rituals after infant death may have on students' ability to cope with such deaths. In the case of Rachel and Sandral, two students who described participating in such rituals, it did help them cope with the loss of their patients. It is also worth exploring whether or not medical students or physicians attend the funerals of patients they have closely worked with. While none of the students in this study did, such attendance may help them cope with patient death since funerals represent a ritual that are usually a part of the grieving process in our society.

\section{Chapter Six Conclusion}

The findings of the last chapter clearly contrast with previous claims that the medical profession views death as a failure (Hooyman and Kiyak 2008; Dickinson and Leming 2007; Dickinson, Still, and Tournier 1999; Rappaport and Witzke 1993). The socialization of medical students surrounding death issues at this particular university seems to also contrast with the qualitative research of death anxiety among medical students at a Northeastern region school in which Rhodes-Kropf et al. (2005) found that students perceived the message that death is a failure from the informal curriculum during their rotations. The majority of students in this study, however, made it clear that they did not perceive any such message during their training or through the formal curriculum. During the interviews it became clear that the majority of students do not think of death to be a failure on the part of medicine as a whole but rather that they accept 
death as a natural process and not something that happens because medicine is limited in its potential to extend lives. It is possible that the students' attitudes towards patient death may change when they become physicians, as noted by some of the students.

There are many areas of this study which are worthy of future research. The idea of patient autonomy and how it affects students' views of death is one such issue. Patient autonomy was often mentioned in descriptions of what constitutes a good death and the changing views of patient autonomy within the medical profession is something that could greatly affect one's experience of losing patients. Lastly, the views of the students in this study concerning physician assisted suicide are worthy of further study. Although the majority of students opposed or were uncertain about physician assisted suicide, many were not opposed to giving enough pain medication to relieve pain even if it may hasten death. Students' opposition to physician assisted suicide may have to do with the fact that some conflated physician assisted suicide with euthanasia as I did not define the term physician assisted suicide in the question.

The findings of this research suggest that within my sample of twenty medical students, the majority do not view death as a failure in general. Exploring why these students refrained from framing death as a failure in general is something that requires further research in the area of death anxiety and the medical profession. While some students mentioned generational gaps as to why their views may differ from the commonly held idea that physicians and individuals in the medical profession view death as a failure, it is still possible that other reasons for this shift exist. The socialization process that takes place during and after medical school is something that shapes future physicians and teaches them how they should think, act and feel when it comes to caring 
for patients. In this study, it appears that this socialization process does not entail the 20 students perceiving or accepting negative views of death. 


\section{Interview Guide}

\section{APPENDICES}

\section{Introduction:}

Thank you for participating in this study. Your interview will really help me not only in terms of completing this class project but will be useful for my thesis as well. I also hope that findings from this study might one day be used not only to give those in academia a better understanding of how medical students cope with death experiences but also to help improve doctor-patient communication.

\section{Offer private room if we are at location preferred by participant that is not} private:

I would like you to know that if you wish to conduct this interview in a private room I can book one in the sociology department in Cavanaugh hall for a later date.

\section{Review confidentiality:}

I want you to know that what you say will be kept confidential. I am the only one who will have access to the audio files of this interview, and I am the one who will be transcribing them. The only person who will have access to the full length transcriptions of the interview is my instructor, Dr. Carrie Foote. Just as it stated in the informed consent form, pseudonyms will be used in place of actual names and locations.

\section{Obtain informed consent:}

I am going to ask you to read and sign an informed consent form before we begin and then we can start with some basic background questions. But this form basically states that this interview is voluntary and covers your rights as a participant and the aims of this research. I will let you have a couple minutes to read it and then I'll let you take the first page and I'll keep the page with the signatures.

\section{Review time frame and responses to questions}

This should only take about an hour, so I'll let you know when it is (4 pm, or whatever time an hour will be) just because I don't want to take too much of your time as I know you must be incredibly busy as a med student. Also, just to reiterate, if you don't want to answer any question you don't have to, just let me know and we'll go on to the next one.

\section{Provide compensation}

Here is the Visa gift card for you and again I want to thank you for being so generous as to give an hour of your time.

\section{Answer any questions before we begin}


Do you have any questions for me before we begin? Any questions about the interview or your rights as a participant? Okay, I'll just go ahead and start with some background questions and I'm going to turn the recorder on now...

\section{Background questions}
a. Race and ethnicity
b. Gender
c. What is your age?
d. What year are you in med school?
e. What was your bachelor's degree in?
f. What area of medicine are you planning on specializing in?

\section{Main Questions...}

\section{Questions about medical school}

1. How did you become interested in attending medical school and wanting to be a doctor?

2. Can you describe what it was like when you took your first anatomy lab in medical school?

a. What emotions or feelings did you experience?

3. How has your third and fourth year compared to the first two years of medical school?

a. What has interacting with patients been like?

\section{Questions about patient interaction}

4. How do you empathize with your patients while maintaining control over your emotions?

a. What level of emotional attachment is appropriate for medical students and doctors to have with their patients?

5. Can you describe any examples of positive-doctor patient interaction or negative doctor-patient interaction that you have seen?

a. Are there any instances that stand out in your mind as something you would like to emulate or avoid?

6. Have you ever had to break bad news to a patient, if not have you ever been present while a doctor had to break bad news to a patient?

a. What was that like for you?

b. What have you been told about how to break bad news?

\section{Questions about death experiences}

7. Can you describe the death of any patients you have experienced and how those deaths affected you? 
8. What were your initial reactions to these deaths?

a. What emotions did you feel?

b. What is considered appropriate when it comes to expressing your emotions amongst other doctors and medical students?

9. What short term and long coping mechanisms do you use to deal with patient deaths?

10. Was that the most emotionally draining experience you've had as a medical student?

a. Was it experiencing a patient death, and if not what was it?

11. Can you describe the different ways you've seen medical students cope with death? And how do you cope with death?

12. How do residents and attendings cope with death compared to medical students, do they view death any differently?

a. I have heard this varies by age and by specialty

13. What kind of relationship do you have with interns, residents and attendings as a medical student?

a. Do they provide support when dealing with patient deaths?

14. What constitutes a good death in your mind?

a. Can you describe any good deaths that you've seen?

b. Can you describe any bad deaths that you've seen?

15. How do you feel about physician assisted suicide in attempting to help to create a good death?

a. Issues of morphine use at end of life care

16. Can you describe any overly aggressive treatment you might have seen concerning end of life care?

a. How did that make you feel?

17. Can you describe any time when it might have been more appropriate to let the patient pass away and they didn't?

a. How did that make you feel?

18. What anxieties do you experience as a medical student?

19. How has working in medicine where you are exposed to death influenced your views about your own mortality?

20. What advice would you give to $2^{\text {nd }}$ year students who are going to start their rotations soon? 
a. What would you tell them about interacting and communicating with patients?

b. What would you tell them about coping with the death of patients? 


\section{Recruitment Flyer}

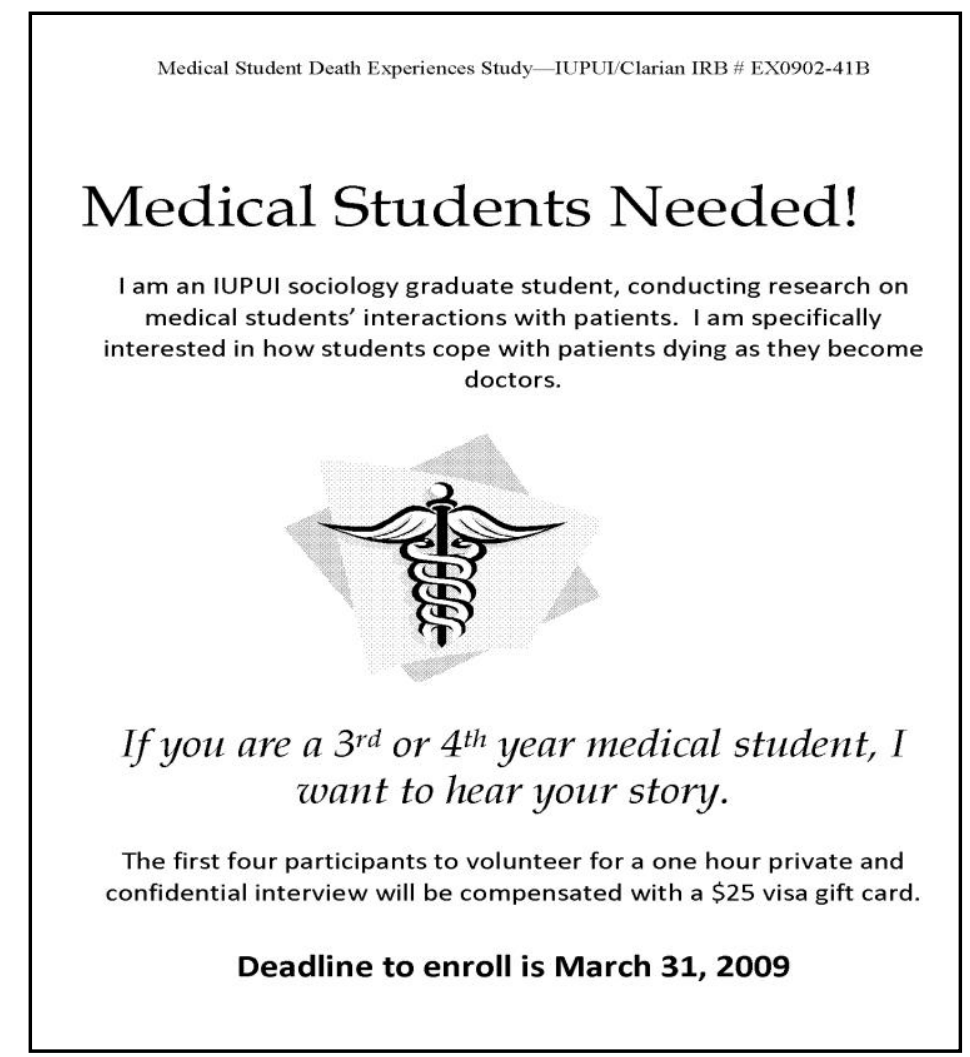

\section{Recruitment Email}

Mr. [Insert Name],

My name is Regina Pessagno and I am a graduate student in the sociology department here at IUPUI. I am currently conducting research on medical students' death experiences and would greatly appreciate it if you would be willing to refer me to any listservs or rosters that have the potential to reach third and fourth year medical students to which I might be able to send my recruitment flyer. The data I collect will be used for a class project this semester and will also go towards my thesis. There are also benefits for medical students including having the opportunity to voice their experiences and being compensated with a visa gift card. If there are any listservs or rosters that you know of which I could distribute my flyer to, please let me know.

If you have any questions about the validity of this research, you may contact my course instructor, Dr. Carrie Foote at foote@iupui.edu or (317) 278-8454.

Please let me know if you have any questions about my research.

Thank you for your time, Regina Pessagno 


\section{Informed Consent Form}

\section{Informed Consent for Medical Students' Death Experiences Study, Spring 2009 IUPUI-Clarian IRB \# EX0903-46B}

Before agreeing to participate in this research study, please read the following information as it pertains to the goals of this research and your rights as a participant.

Purpose of study: This research is being conducted in order to gain a better understanding of medical student's experiences related to their interactions with patients concerning the issues of death and dying. Specifically, as a researcher I am interested in obtaining data that will help to explore the issue of death anxiety among medical students. The end results of this research will hopefully give us a better understanding of how medical students cope with death experiences.

Explanations of procedures: Participation in this study is voluntary and will include the completion of one in depth interview lasting approximately one hour in length. This interview will be recorded with a digital audio voice recorder with your permission. Also with your permission the data collected during this recording will be transcribed and analyzed for research purposes.

Confidentiality: Confidentiality is a top priority in this study. The only person who will hear and transcribe the interviews will be me, Regina Pessagno. The only person who the original transcripts will be made available to is my thesis advisor, Dr. Carrie Foote. Pseudonyms will be used in place of actual names and locations as to limit the chance of public recognition of persons or places that are discussed in the interview. The audio files will be destroyed once they have been transcribed.

Right to withdrawl: Participation in this study is voluntary; there will be no penalty for refusing to participate. You may decline to participate at any time, including after the interview process has begun. You may also decline to answer any question that is asked during the interview.

Payment to subject for participation in research: You will receive one $\$ 25$ visa gift card for your participation in this study.

Risks of taking part in this study: The risks of this study are minimal. However, you may experience discomfort or emotional distress while discussing your experiences with death.

Benefits of taking part in this study: It may be helpful to discuss your experiences with death as a medical student in terms of exploring how you interact with patients. Also, you may find the chance to voice your experiences gives you satisfaction.

Questions and concerns: Any questions or concerns regarding this research project can be directed to the faculty member supervising this research, Dr. Carrie Foote, who can be reached at (317) 278-8454 or foote@iupui.edu. If you have any questions or concerns in the future, I, Regina Pessagno, can be reached at (317) 727-0390 or rpessagn@iupui.edu. Questions regarding rights as a research participant should be regarded to IUPUI/Clarian Research Compliance Administration office at (317) 278-3458. 


\section{REFERENCES}

Anspach, Renee. 1993. Deciding Who Lives: Fateful Choices in the Intensive Care Nursery. Berkeley and Los Angeles: University of California Press.

Braddock, Clarence H. and Mark R. Tonelli. 1998. "Physician-Assisted Suicide." University of Washington School of Medicine.

<http://depts.washington.edu/bioethx/topics/pas.html>. Retrieved April 8 ${ }^{\text {th }}, 2010$.

Bury, Mike, Jonathan Gabe and Mary Elston. 2004. Key Concepts in Medical Sociology. CA: Sage Publishing.

Charmaz, Kathy. 2006. Constructing Grounded Theory: A Practical Guide Through Qualitative Analysis. Thousand Oaks, California: Sage Publications.

Chin, J.J. 2002. "Doctor-patient Relationship: from Medical Paternalism to Enhanced Autonomy.” Singapore Medical Journal 43(3):152-155.

Coulehan, John L. 1995. "Tenderness and Steadiness: Emotions in Medical Practice." Literature and Medicine 14(2):222-236.

Daniel, Eileen L., ed. 2010. Taking Sides: Clashing Views in Health and Society. $9^{\text {th }}$ edition. New York: McGraw-Hill.

DelVecchio Good, Mary-Jo, Nina M. Gadmer, Patricia Ruopp, Matthew Lakoma, Amy M. Sullivan, Ellen Redinbaugh, Robert M. Arnold and Susan D. Block. 2004. "Narrative Nuances on Good and Bad Deaths: Internists' Tales from HighTechnology Work Places." Social Science and Medicine 58:939-953.

Dickinson, George E. and Algene A. Pearson. 1980. "Death Education and Physicians' Attitudes Toward Dying Patients." Journal of Death and Dying 11(2):167-174.

Dickinson, George E. and Michael R. Leming. 2007. Understanding Dying, Death, and Bereavement. $6^{\text {th }}$ edition. Belmont, California: Thompson Wadsworth.

Dickinson, George E., Robert E. Tournier and Brenda J. Still. 1999. “Twenty Years Beyond Medical School: Physicians' Attitudes Toward Death and Terminally Ill Patients." Archive of Internal Medicine 159:1741-1744.

Dinsmore, Charles E., Steven Daugherty and Howard Zeitz. 2001. "Student Responses to the Gross Anatomy Laboratory in a Medical Curriculum." Clinical Anatomy $14: 231-236$

Donohoe, Martin. 2002. "Reflections of Physician-Authors on Death: Literary Selections Appropriate for Teaching Rounds.” Journal of Palliative Medicine 5(6):843-848. 
Esterberg, Kristin G. 2002. Qualitative Methods in Social Research. New York: McGraw Hill.

Finkelstein, Peter and Lawrence Mathers. 1990. "Post-Traumatic Stress Among Medical Students in the Anatomy Dissection Laboratory." Clinical Anatomy 3:219-236.

Fox, Renee. 1981. "The Sting of Death in American Society." Social Service Review 55(1):42-59.

Friel, Patrick. 1982. Death and Dying. Annals of Internal Medicine 97(5):767-771.

Goldberg, Judah L. 2008. "Humanism or Professionalism? The White Coat Ceremony and Medical Education." Academic Medicine 83(8):715-722.

Hafferty, Frederic W. 1988. "Cadaver Stories and the Emotional Socialization of Medical Students." Journal of Health and Social Behavior. 29(4):344-356. 1991. Into the Valley: Death and the Socialization of Medical Students. New Haven: Yale University Press.

— 2000. "Reconfiguring the Sociology of Medical Education: Emerging Topics and Pressing Issues." Pp. 238-257 in Handbook of Medical Sociology edited by Bird, Chloe, Peter Conrad and Allen Fremont. New Jersey: Prentice Hall Publishing.

Hooyman, Nancy R. and H. Asuman Kiyak. 2008. Social Gerontology: A Multidisciplinary Perspective. $6^{\text {th }}$ edition. Boston, MA: Allyn and Bacon.

Kane, Anne C. and John D. Hogan. 1985. "Death Anxiety in Physicians: Defensive Style, Medical Specialty, and Exposure to Death." Journal of Death and Dying 16(1):11-22.

Kinghorn, Warren A. 2010. "Medical Education as Moral Formation: An Aristotelian Account of Medical Professionalism." Perspectives in Biology and Medicine 53(1):87-105.

Kleinman, Sherryl and Allen C. Smith. 1989. "Managing Emotions in Medical School: Students' Contacts with the Living and the Dead." Social Psychology Quarterly 52(1):56-69.

Larson, Eric B. and Xin Yao. 2005. "Clinical Empathy as Emotional Labor in the PatientPhysician Relationship." Journal of American Medical Association 293(9):11001106.

Ludemer, Kenneth M. 1999. "Instilling Professionalism in Medical Education." Journal of American Medical Association 282(9):881-882. 
MacLeod, Roderick D. 2001. "On Reflection: Doctors Learning to Care for People Who Are Dying." Social Science and Medicine 52:1719-1727.

Marcum, James. 2008. "Reflections on Humanizing Biomedicine." Perspectives in Biology and Medicine 51(3):390-405.

Pellegrino, Edmund D. and David C. Thomasma. 1987. "The Conflict Between Autonomy and Beneficence in Medical Ethics: Proposal for a Resolution." Journal of Contemporary Health Law and Policy 3(23):23-46.

Rappaport, William and Donald Witzke. 1993. "Education About Death and Dying During the Clinical Years of Medical School.” Surgery 113(2):163-165.

Ratanawongsa, Neda, Karen E. Hauer, and Arianne Teherani. 2005. "Third-Year Medical Students' Experiences with Dying Patients During the Internal Medicine Clerkship: A Qualitative Study of the Informal Curriculum." Academic Medicine 80(7):641-647.

Rhodes-Kropf, Jennifer., Sharon S. Carmody, Deborah Seltzer, Ellen Redinbaugh, Nina Gadmer, Susan Block, and Robert M. Arnold. 2005. "This is Just Too Awful; I Just Can't Believe I Experienced That...”: Medical Students' Reactions to Their "Most Memorable" Patient Death. Academic Medicine 80(7):634-640.

Rooney, Pauline. 2005. Researching from the Inside - Does it Compromise Validity? A Discussion. Issue 3. Retrieved April 9, 2009. http://arrow.dit.ie/ltcart/5/

Schutt, Russell K. 2006. Investigating the Social World: The Process and Practice of Research. 5 ed. Thousand Oaks, California: Sage Publications.

Seidman, Irving. 2006. Interviewing as Qualitative Research: A Guide for Researchers in Education and the Social Sciences. $3^{\text {rd }}$ edition. New York: Teachers College Press.

Weitz, Rose. 2001. The Sociology of Health, Illness and Health Care: A Critical Approach. Belmont, CA: Wadsworth Publishing.

Williams, Cynthia M., Cindy C. Wilson and Cara H. Olsen. 2005. "Dying, Death, and Medical Education: Student Voices.” Journal of Palliative Medicine 8(2):372381. 


\section{CURRICULUM VITAE \\ REGINA M. PESSAGNO}

\section{Degrees}

EDUCATION

August 2010 M.A. in Sociology, Indiana University- Indianapolis

Thesis: Dealing with Death: Medical Students' Experiences with Patient Loss

May 2008 B.A. in Sociology with High Distinction, Indiana University-Indianapolis

Research Interests

Critical Theory, Social Control, Medical Sociology

\section{SCHOLARSHIPS, HONORS, AND AWARDS}

2010 Service Learning Assistant Scholarships, IUPUI Center for Service Learning

2009 Sociology Department Thesis Grant (\$500)

2009 Teaching Assistant Position with Full Tuition Waiver, IUPUI Department of Sociology

2009 Service Learning Assistant Scholarship, IUPUI Center for Service Learning

2008 Service Learning Assistant Scholarship, IUPUI Center for Service Learning

2008 Research Assistant Position with Full Tuition Waiver, IUPUI Department of Sociology

2007 Inducted into Golden Key International Honor Society

\section{ACADEMIC EXPERIENCE}

\section{Research Experience}

2010 Research Assistant for Dr. Tamara Leech. Assisted with survey conducted among R100 Introductory to Sociology courses.

2009 Research Assistant for Dr. Carrie Foote. Transcribed interviews coded and entered data into Vivo 8 software, literature reviews, and report writing for two large federally funded projects: NIH R03 Exploring Intentional Childbearing among People with HIV; Department of Defense - Understanding the Long-Term Care Experiences of Vietnam Veteran with Combat Related Limb-Loss funded through the Indiana-Ohio Center for Traumatic Amputee Rehabilitation Research.

2009 Service Learning Assistant for Dr. Carrie Foote. Data entry into SPSS and Vivo software, analyses and report writing for the 2009 Indiana HIV Needs Assessment Study.

2009 Research Assistant for Dr. Robert Aponte. Literature reviews and report writing for an introductory review article for Marriage and Family Review. 
2008 Research Assistant for Dr. Patricia Wittberg. Collected data concerning various religious organizations for her work "New Ecclesial Movement Organizations in Roman Catholicism: A Study of Ideology."

\section{Teaching Experience}

2010 Guest Lecturer, "Introduction to NVIVO 8: A Qualitative Software." Graduate course in Qualitative Methodology, R659.

2009 Teaching Assistant for Dr. Robert Aponte. Introduction to Sociology and Drugs, Alcohol and Society. Responsibilities included tracking attendance, conducting study sessions, drafting questions for exams, and meeting with students outside of class.

2008 Service Learning Assistant for Dr. Wan Ning Bao. Introduction to Sociology. Duties included assisting students with placements for service learning projects, serving as a liaison between agencies, students and instructors, and keeping track of students' projects over the course of the semester.

\section{PROFESSIONAL PUBLICATIONS AND PRESENTATIONS}

\section{Peer Reviewed Publications}

2009 Robert Aponte, with the assistance of Regina Pessagno. "The Communications Revolution and its impact on the Family: Significant, Growing, but Skewed and Limited in Scope." Marriage and Family Review, 45:6-8, August 2009, pp. 576586.

\section{Applied Research Reports}

2009 Carrie Foote, Jodie Atkinson, Regina Pessagno, Kyle Henderson. Final Results: Qualitative Phase II Interview Project. A Component of the Amputee Veteran Research Project. Report prepared for the Indiana-Ohio Center for Traumatic Amputation Rehabilitation Research.

2009 Carrie Foote, Regina Pessagno, Sarah Lynn. Final Results: Indiana Consumer Survey. A Component of the 2009 HIV Services Needs Assessment. Pp. 1-64. Report prepared for the Indiana State Department of Health, HIV/STD Division.

2009 Carrie Foote, Regina Pessagno, Sarah Lynn. Final Results: Indiana Provider Survey. A Component of the 2009 HIV Services Needs Assessment. Pp. 1-45. Report prepared for the Indiana State Department of Health, HIV/STD Division

\section{Presentations}

2010 Regina Pessagno. "Dealing with Death: Medical Students' Experiences of Patient Loss." Joint Conference of the Midwest Sociological Society and North Central Sociological Association. 
2009 Carrie Foote, Seth Messenger, Jodie Atkinson, Regina Pessagno. The LongTerm Experiences of Vietnam Veteran Amputees. Annual meeting for the Society for the Study of Social Problems, San Francisco, August 7-9.

\section{PROFESSIONAL AFFILIATIONS}

Society for the Study of Social Problems

American Sociological Association

Midwest Sociological Society 